\title{
Chapter 4 \\ Abrupt Climate Changes and Emerging Ice-Ocean Processes in the Pacific Arctic Region and the Bering Sea
}

\author{
Jia Wang, Hajo Eicken, Yanling Yu, Xuezhi Bai, Jinlun Zhang, \\ Haoguo Hu, Dao-Ru Wang, Moto Ikeda, Kohei Mizobata, \\ and James E. Overland
}

\begin{abstract}
The purpose of this chapter is to reveal several emerging physical ice-ocean processes associated with the unprecedented sea ice retreat in the Pacific Arctic Region (PAR). These processes are closely interconnected under the scenario of diminishing sea ice, resulting in many detectable changes from physical environ-
\end{abstract}

\footnotetext{
J. Wang $(\bowtie)$

Great Lakes Environmental Research Laboratory (GLERL),

National Oceanic and Atmospheric Administration, Ann Arbor, MI, USA

e-mail: jia.wang@noaa.gov

H. Eicken

Geophysical Institute, University of Alaska Fairbanks, Fairbanks, AK, USA

Y. Yu

Arctic Science Center, Applied Physics Laboratory, University of Washington,

Seattle, WA, USA
}

J. Zhang

Applied Physics Laboratory, University of Washington, Seattle, WA, USA

X. Bai • H. Hu

Cooperative Institute for Limnology and Ecosystems Research (CILER),

School of Natural Resources and Environment, University of Michigan,

Ann Arbor, MI, USA

D.-R. Wang

Hainan Marine Development and Design Institute, Hainan, China

M. Ikeda

Graduate School of Earth and Environmental Sciences,

Hokkaido University, Sapporo, Japan

K. Mizobata

Department of Ocean Sciences, Tokyo University of Marine Science

and Technology, Tokyo, Japan

J.E. Overland

Pacific Marine Environmental Laboratory, National Oceanic and Atmospheric

Administration, 7600 Sand Point Way NE, Seattle, WA 98115, USA 
ment to ecosystems. Some of these changes are unprecedented and have drawn the attention of both scientific and societal communities. More importantly, some mechanisms responsible for the diminishing sea ice cannot be explained by the leading Arctic Oscillation (AO), which has been used to interpret most of the changes in the Arctic for the last several decades. The new challenging questions are: (1) What is the major forcing? (2) Is the AO, the DA, or their combination, contributing to the sea ice minima in recent years? How do we use models to investigate the recent changes in the PAR. Is the heat transport through the Bering Strait associated with the DA? What processes accelerate sea ice melting in the PAR?

Keywords Arctic Dipole Anomaly • Arctic summer ice minima $\bullet$ Landfast ice • Ice/ocean albedo feedback

\subsection{Introduction}

The northern North Pacific Ocean, including the Bering Sea, is among the most productive marine ecosystems in the world, as evidenced by large populations of marine fish, birds, and mammals. Fish and shellfish from these regions constitute more than $10 \%$ of total seafood harvest of the world and about $52 \%$ of the U.S. (PMEL 2000). As a result, the productivity is critical not only to the U.S. economy, but also to the economy of surrounding countries.

The Bering Sea (Fig. 4.1) is a complex semi-enclosed sea with a shallow, broad shelf, a shelf break, and deep basins. The ocean circulation pattern is complicated. The Alaskan Stream (AS) mainly flows along the Aleutian Peninsula and provides some of its water via Aleutian passes to the Bering Slope Current (BSC) and to the Aleutian North Slope Current (ANSC; Stabeno et al. 1999; Hu and Wang 2010). The BSC extends into two coastal currents: the Anadyr Current (AC), which flows along eastern Siberia into the Chukchi Sea through the western side of the Bering Strait, and the East Kamchatka Current (EKC), which flows southwestward along the Koryak and Kamchatka peninsula. Numerous sites of mesoscale eddy generation possibly exist within the AS and BSC, due to baroclinic instability interacting with the sloping shelfbreak (Wang and Ikeda 1997; Mizobata et al. 2002, 2006, 2008). The basic schematic surface circulation pattern, based on available observational evidence (Kinder and Coachman 1978; Stabeno and Reed 1994), is fairly well known (Fig. 4.1). The interaction or exchange between the shelf and deep basins is a typical phenomenon that significantly influences primary and secondary productivities (Mizobata et al. 2002; Mizobata and Saitoh 2004).

In the Bering Sea and the southern Chukchi Sea, seasonal sea-ice cover is an important predictor of regional climate (Niebauer 1980; Wang and Ikeda 2001). Sea-ice extent also influences ocean circulation patterns, thermal structure, water stratification, and deep convection (Wang et al. 2010) because: (1) wind stress drag is different in magnitude over the water surface with and without ice cover (Pease et al. 1983); (2) the albedo of ice differs from that of water; thus, prediction of the sea-ice extent (i.e., edge) is crucial to predicting the ocean mixed layer and ocean 


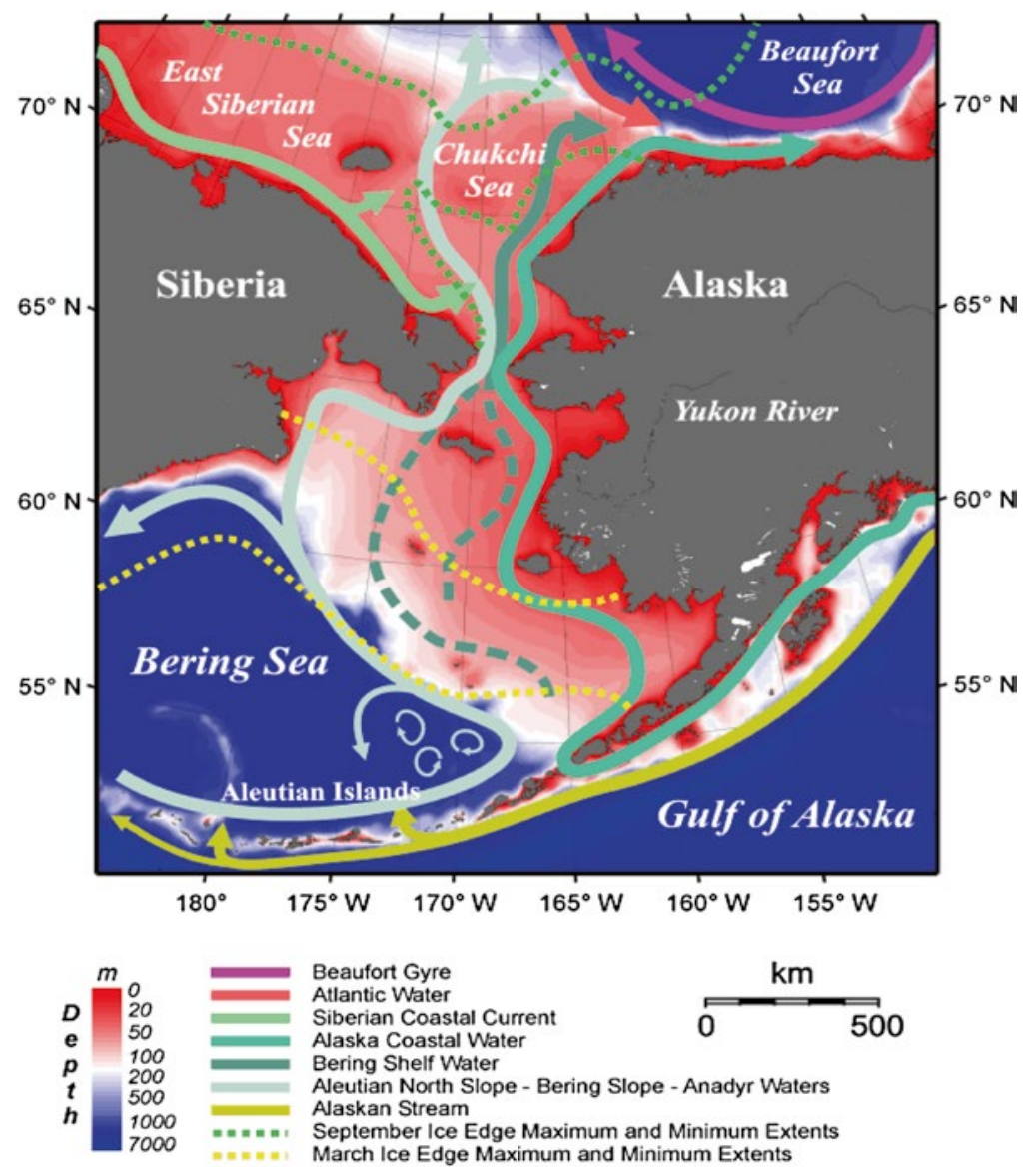

Fig. 4.1 Topography and bathymetry of the Bering Sea and the western/Pacific Arctic region $(P A R)$, and schematic circulation systems (by colored arrows). Water depths are in meters (Courtesy of T. Weingartner, University of Alaska Fairbanks)

circulation, and thus, to predicting primary and secondary productivities (Springer et al. 1996); and (3) spring ice-melt freshwater increases stratification in the upper layer, which may enhance phytoplankton blooms. In addition, climate change, through its effect on the timing of ice melting, would determine the timing of phytoplankton and zooplankton blooms. As a result, sea-ice conditions and the ecosystem in the Bering Sea are driven mainly by atmospheric and oceanic forcing, from tidal, synoptic, and seasonal to interannual and decadal time scales.

The Western Arctic Ocean, with a freshwater and heat pathway to the Bering Sea via the Bering Strait, includes the Eastern Siberian Sea, the Chukchi Sea, and the Beaufort Sea (Fig. 4.1). There are two important current systems in the regions: the Alaska Coastal Current (ACC) and the Eastern Siberian Current (ESC), which are both driven by the freshwater. Two branches flow through the Central Channel and Herald Canyan (Woodgate et al. 2005), and join the Beaufort Slope Current 


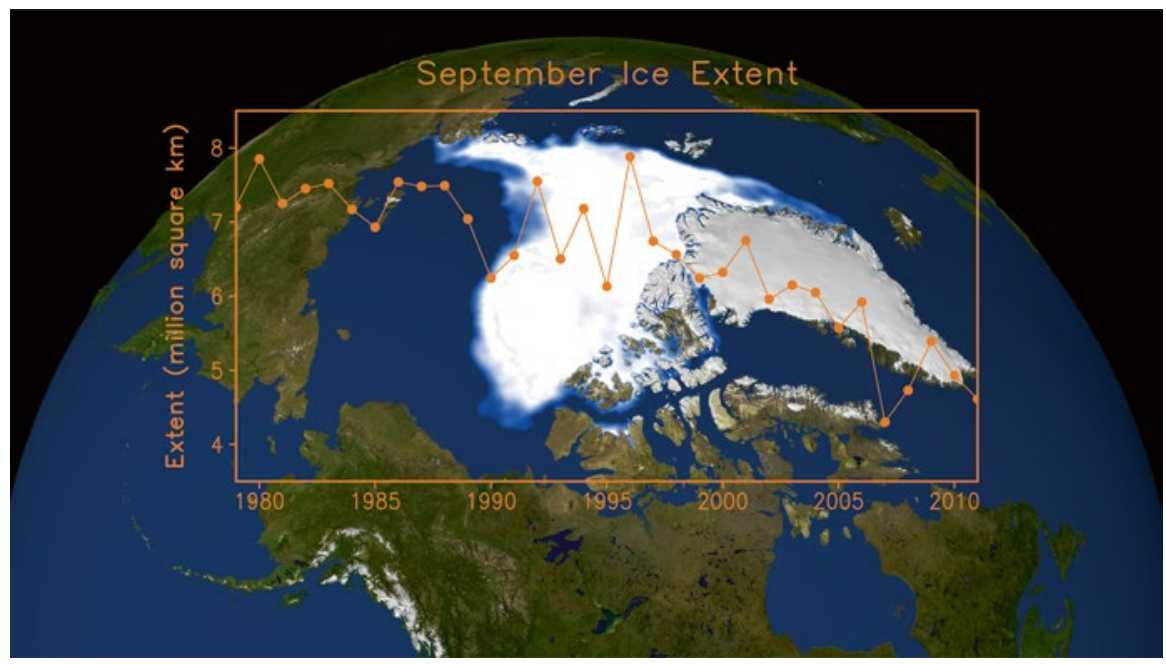

Fig. 4.2 Time series (1979-2011) of average September sea ice extent from satellite measurements. The background is the spatial distribution of the recording-breaking minimum sea ice extent on September 14, 2007 (all time low)

(Pickart 2004). The surface Beaufort Gyre is an anticyclonic circulation for both the ocean and sea ice, driven by the Beaufort high pressure system. Significant changes in sea ice cover and ice-related physical and ecological phenomena occurred in the last decade, particularly in the PAR. In particular, the extent of Arctic sea ice reached its all time low in September 2007, shattering all previous lows (Serreze et al. 2007; Comiso et al. 2008; Gascard et al. 2008; Wang et al. 2009a) since satellite recordkeeping began nearly 30 years ago (Fig. 4.2). The Arctic sea ice extent in September 2007 stood at $4.3 \cdot 10^{6} \mathrm{~km}^{2}$. Compared to the long-term (1979-2000) minimum average, the new minimum extent was lower by about $2.56 \cdot 10^{6} \mathrm{~km}^{2}-$ an area about the size of Alaska and Texas combined, or 10 United Kingdoms. The cause of this significant ice loss was thought to be the combined effects of Arctic Oscillation (AO)-induced warming (Wang and Ikeda 2000) due to natural climate variability and exporting of multiyear ice (Rigor and Wallace 2004; Steele et al. 2004), the climate warming trend due to greenhouse gases (caused by anthropogenic activities), and the culmination of an ice/ocean-albedo positive feedback (Ikeda et al. 2001, 2003; Wang et al. 2005b).

As the Arctic environment changes at a faster rate than the rest of the world, an emerging concern is how soon the Arctic Ocean will become ice-free in summer (Wang and Overland 2009). The diminishing summer ice cover in the western Arctic can have significant impacts on the Arctic and subarctic marine ecosystems (Jin et al. 2011; Deal et al. 2014, this volume), including a lengthened algae bloom period due to increasing absorption of solar radiation (Grebmeier et al. 2006). The present Bering ecosystems and food webs have been experiencing significant changes due to an increase in water temperature (Overland and Stabeno 2004; 
Grebmeier et al. 2010). The Chukchi Sea ecosystems will experience significant changes due to more open water, lengthened growth seasons, and an abundance of biomass. Seasonal landfast ice along the Alaskan Arctic coast (Eicken et al. 2006; Mahoney et al. 2007) would melt early and form late, causing a shortening of whaling and fishing seasons (autumn and spring) for the local community. These emerging consequences will alter not only the ecosystems (Jin et al. 2011; Deal et al. 2014, this volume), but also the lifestyle of the native community and commercial activity in the Arctic. Such impacts are far-reaching and inherently interdisciplinary.

Since 1995, the annual sea ice variability shows that a series of record lows in summer Arctic sea ice extent were set (Fig. 4.2). During the same time, the AO index became mostly neutral or even negative (Overland et al. 2008; Maslanik et al. 2007), suggesting a weak link between the $\mathrm{AO}$ and the rapid sea ice retreat. Whenever the Arctic sea ice has reached a new minimum, searching for mechanisms responsible for the individual year's event was appealing (Serreze et al. 2007; Nghiem et al. 2007; Gascard et al. 2008). However, there has been no convincing physical explanation that accounts for the complete series of such events (1995, 1999, 2002, 2005, 2007, and 2008). Wang et al. (2009a) proposed that the Arctic Dipole Anomaly (DA) pattern is the major forcing in advecting sea ice out of Arctic Ocean under the thinning ice conditions (which is due to long-term cumulative thermodynamic effect, or ice/ocean albedo feedback), causing a series of Arctic ice minima since 1995.

This chapter, in addition to Overland et al. (2014, this volume) provides a large picture of the recent and future change in meteorology in the PAR, provides an discussion and explanation of several emerging sea ice-related processes in the PAR and the Bering Sea, and is organized as follows: After the introduction, Sect. 4.2 describes data and methods used. Section 4.3 investigates the DA and summer sea ice minima. Section 4.4 shows the modeling studies of ice minima and their relationship to the dynamic (wind) and thermodynamic (including ice/ocean albedo feedback) forcings. Section 4.5 investigates the Bering Strait heat transport (Clement Kinney et al. 2009, 2014, this volume) and its possible relation to the DA. Section 4.6 discusses the modeling studies of landfast ice along Beaufort coast using a Coupled Ice-Ocean Model (CIOM). Section 4.7 investigates seasonal and interannual variability of the Bering Sea cold pool using the CIOM. A positive air-ice-sea feedback loop is proposed and discussed in Sect. 4.8. Section 4.9 summarizes the conclusions and proposes future work.

\subsection{Data and Methods}

The average September sea ice extent, archived at the National Snow and Ice Data Center (NSIDC), was obtained from SMMR (Scanning Multichannel Microwave Radiometer) for 1978-1987 and SSM/I (Special Sensor Microwave Imager) for the period 1987 to present based on the NASA Goddard algorithm (Comiso et al. 2008). The monthly NCEP (National Centers for Environmental Prediction) Reanalysis dataset from 1948 to 2010 were used to derive the EOF (Empirical Orthogonal 
Function) modes for individual seasons: winter (DJF), spring (MAM), summer (JJA), and autumn (SON). Oceanic heat transport via the Bering Strait was calculated using in situ shipboard measurements and satellite-measured SST across the Bering Strait (Mizobata et al. 2010). A Pan-arctic Ice-Ocean Modeling and Assimilation System (PIOMAS, Zhang et al. 2008a, b) was used to simulate the sea ice and ocean circulation for the period 1978-2009 using daily NCEP forcing.

Regional CIOM was used in the Chukchi, Beaufort, and Bering Seas to investigate the ice-ocean systems and the responses to climate change in recent years. For a detailed description of development of the CIOM, readers should refer to Yao et al. (2000) and Wang et al. (2002, 2010), which was applied to the pan-Arctic Ocean (Wang et al. 2004, 2005a; Wu et al. 2004; Long et al. 2012), Chukchi-Beaufort seas (Wang et al. 2003, 2008), and the Bering Sea (Wang et al. 2009b; Hu and Wang 2010; Hu et al. 2011). The ocean model used is the Princeton Ocean Model (POM) (Blumberg and Mellor 1987), and the ice model used is a full thermodynamic and dynamics model (Hibler 1979, 1980) that prognostically simulates sea-ice thickness, sea ice concentration (SIC), ice edge, ice velocity, and heat and salt flux through sea ice into the ocean.

\subsection{Leading Climate Forcing: Arctic Dipole (DA) Pattern}

The EOF analysis of the NCEP reanalysis dataset (1948-2010) shows the AO as the first mode, and the DA as the second mode (Wang et al. 1995, 2009a; Wu et al. 2006; Watanabe et al. 2006) (Fig. 4.3). The AO has one annular (circled) center covering the entire Arctic, producing zonal wind anomalies. The AO variance (intensity) is strongest in winter (63\%), and decreases in magnitude from spring (61\%), summer (50\%), to autumn (49\%). The DA (Fig. 4.3) differs from the AO in all seasons because the anomalous SLP has two action centers in the Arctic. In contrast to the AO-driven wind anomaly, which is either cyclonic or anticyclonic during the positive or negative phase of the AO (Proshutinsky and Johnson 1997; Wu et al. 2006), the resulting wind anomaly driven by the DA is meridional. During a positive phase of the DA (i.e., the SLP has a positive anomaly in the Canadian Archipelago and negative one in the Barents Sea), the anomalous meridional wind blows from the western to the eastern Arctic, accelerating the Trans-polar Drift Stream (TDS; see the red-dashed arrow) that flushes more sea ice out of the Arctic into the Barents and Greenland Seas (Wu et al. 2006; Watanabe et al. 2006). During the negative phase of the DA, the opposite scenario occurs, i.e., more sea ice remains in the western Arctic (Watanabe et al. 2006).

Note that the intensity of the DA increases from winter (13\%) and spring (14\%) to summer $(16 \%)$ and autumn $(16 \%)$. The variance ratio of DA to $\mathrm{AO}$ is 0.21 for winter, 0.23 for spring, 0.32 for summer, and 0.33 for autumn. This pattern indicates that the DA-derived anomalous wind plays a more important role in summer and autumn during the melting and freezing seasons, or during the thinning ice season, than winter with thicker ice. The second noticeable feature is that the orientation of 
EOF1: AO
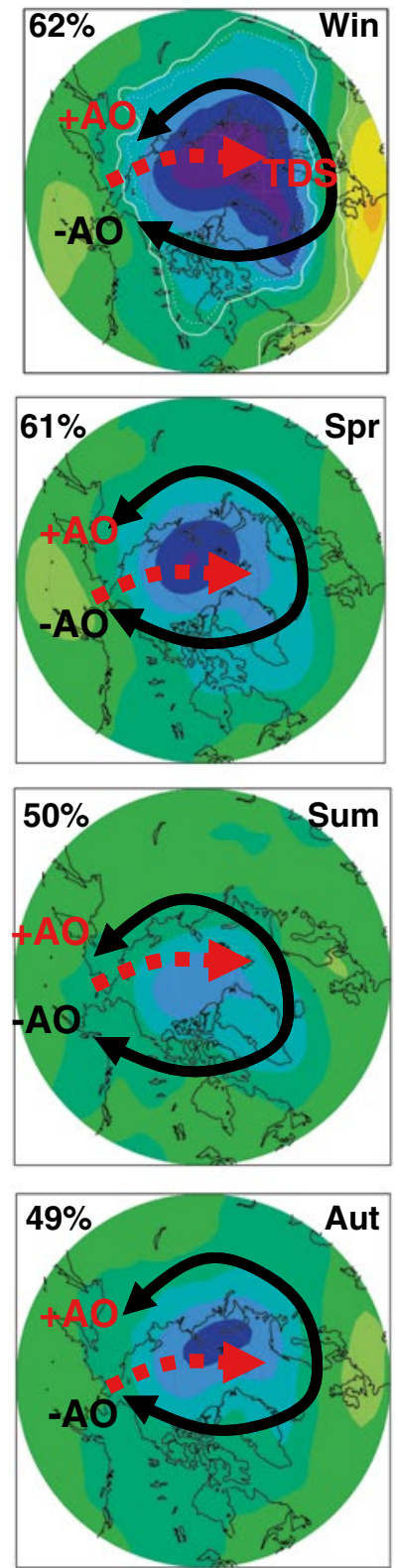

EOF2: DA
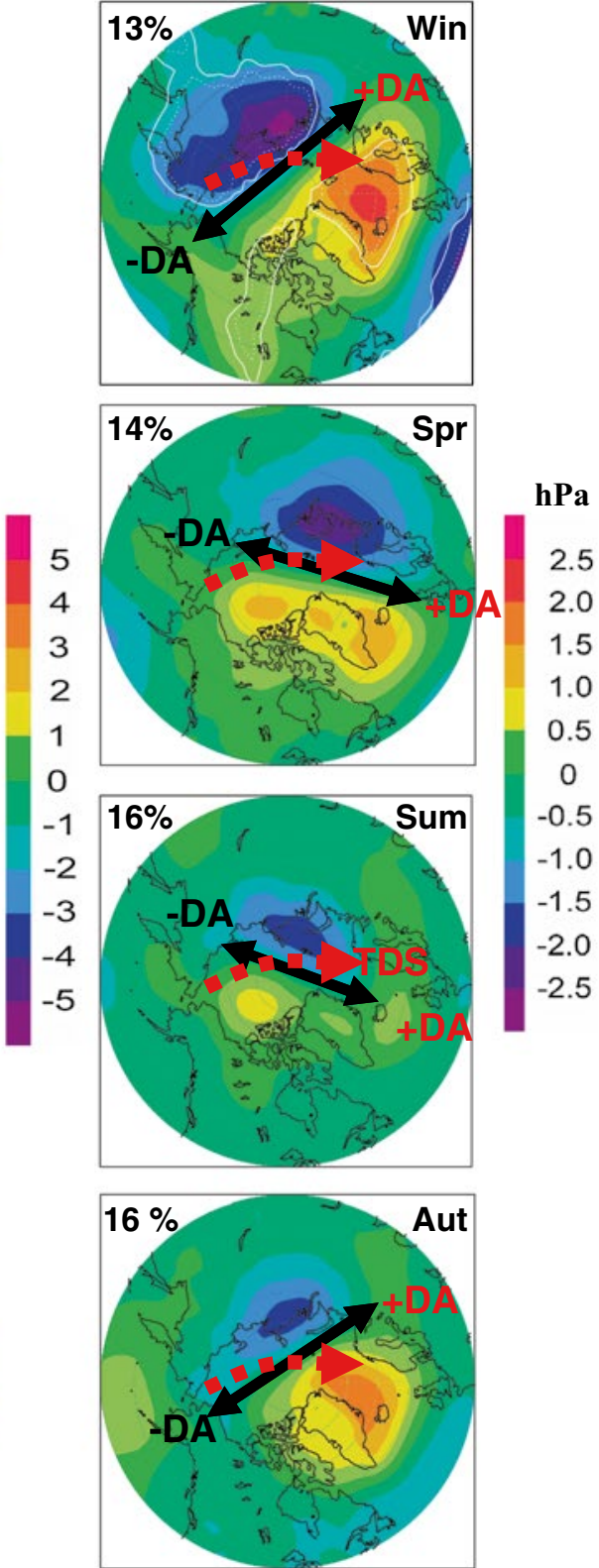

Fig. 4.3 Seasonal variations of regression maps of the first two leading modes (AO and DA) to the winter, spring, summer, and autumn mean Northern Hemisphere SLP field using the NCEP Reanalysis dataset from 1948 to 2010 . Contour intervals are $0.5 \mathrm{hPa}$ (see color bars). The black arrows on the left column indicate the cyclonic (anticlockwise, divergent) wind anomaly during the $+\mathrm{AO}$ phase (which promotes advection of sea ice out of Arctic via Fram Strait) and anticyclonic (clockwise, convergent) wind anomaly during the $-\mathrm{AO}$ phase. On right column, the black arrows indicate that the wind anomaly blows from the western to the eastern Arctic during the +DA phase that accelerates the TDS (in red-dashed arrows), and vice versa during the -DA phase that slows down the TDS 
the maximum wind anomalies are more parallel to TDS-Fram Strait during spring and summer than winter and autumn, indicating spring and, in particular, summer DA are more effective in advecting sea ice to the Nordic seas than the winter and autumn during a positive DA phase. The third feature is that both AO and DA have seasonal variations.

During the positive/negative AO (i.e., when Arctic SLP has a negative/positive anomaly), a cyclonic/anticyclonic wind anomaly occurs, indicating a sea ice divergence/convergence. The divergence (anomalous cyclonic circulation) of sea ice leads to anomalous ice export, while the convergence results in retention of sea ice inside the Arctic Ocean (Proshutinsky and Johnson 1997; Wu et al. 2006). Thus, the +DA pattern is the more effective, direct driver of the Arctic sea ice (including multiple year ice (Maslanik et al. 2011)) export from the western Pacific Arctic to the northern Atlantic, as compared to the +AO. Kwok et al. (2004) tried to establish the relationship between the Fram Strait ice flux with the NAO index (see their Fig. 4.6e) using a 24-year time series of sea ice flux, which is not significant. A better, but not at $95 \%$ significance level, linear relationship was obtained after removing the strong -NAO cases (5 years), with large scattering (see their Fig. 4.6f), suggesting the weak correlation. Actually, the best relationship of sea ice flux was found to be with the sea-level pressure (SLP) difference across the Fram Strait (see their Fig. 4.6c), suggesting the DA is the major forcing, rather than NAO/AO (Wang et al. 2009a).

We conducted the cross composite analysis of both phases of the DA and the AO. A matrix was constructed based on the combination of the two leading drivers that account for about $65-76 \%$ of the total variance. Following Wang et al. (2009a), the Arctic climate patterns can be defined by the following four climate states using $\mathrm{AO}$ and DA indices of larger than $\pm 0.6:(1)+\mathrm{AO} /+\mathrm{DA},(2)+\mathrm{AO} /-\mathrm{DA},(3)-\mathrm{AO} /+\mathrm{DA}$, and (4) $-\mathrm{AO} /-\mathrm{DA}$. It was found that a positive DA is the key, regardless of the sign of the $\mathrm{AO}$, to flushing sea ice out of Arctic due to its dominant meridional wind anomaly (Maslanik et al. 2007), while the wind anomaly driven by a negative DA can retain sea ice in the western Arctic (Fig. 4.3). In other words, the DA is dynamically more important and more effective than the AO in driving sea ice out of the Arctic Basin. These four states can represent major atmospheric circulation patterns in the Arctic, which are the major drivers of sea ice and ocean circulation. The importance of the air temperature advection by the DA is consistent with the recent findings by Overland et al. (2008). They concluded that the warming anomalies in the central Arctic during 2000-2007 are driven by meridional advection from the Pacific sector.

Figure 4.4 shows a scatter plot between the summer DA index (x-axis) and winter-spring mean DA index (y-axis) for the period since 1995. The figure examines whether the persistency of the DA may cause a series of ice minima. Most of the ice minima years fall into the first quadrant, which indicates that, when the +DA persists from winter, spring, all the way to summer, more ice would be advected out of the Arctic Ocean, leading to ice minima in 1995, 2002, 2005, 2007, 2008, and 2009; the 2007 ice minimum is the all time low (see Fig. 4.2). Although the -DA occurs in the winter-spring period when sea ice is normally retained in the Pacific Arctic, a strong +DA in summer can reverse the process, effectively advecting sea 


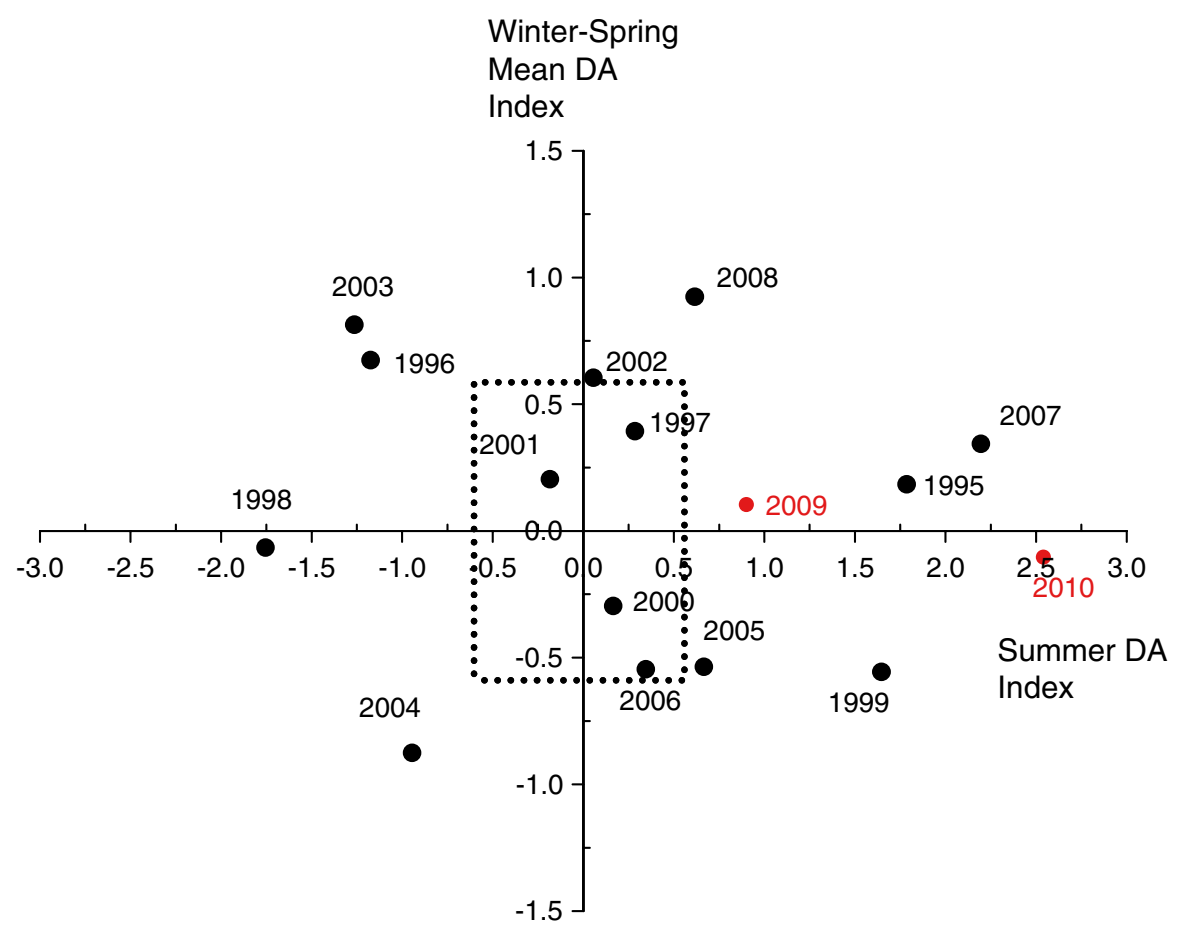

Fig. 4.4 Scatter plot between the summer DA index (x-axis) and winter-spring mean DA index (y-axis) from 1995 to 2010. The box outlined by dotted lines indicates the 0.6 index threshold; the indices greater than 0.6 are considered significant DA years

ice to the Nordic seas and leading to ice minima in 1999, 2005, and 2010 (4th quadrant). Therefore, the summer DA is the most critical dynamically, since summer sea ice is more mobile than winter ice because summer sea ice is about $1 \mathrm{~m}$ thinner than winter ice. Because the summer anomalies have weaker AO-related SLP signals, the +DA-derived wind anomalies are more effective in reducing sea ice, primarily due to two thermodynamic effects, i.e., advecting warm air from land to the ocean and enhancing melt through a positive ice-albedo feedback (Ikeda et al. 2001; Wang et al. 2005b).

Recently, Ikeda (2012) reveals an important finding that the DA (or Arctic Dipole Mode, ADM) has different frequency spectra between fall-winter (several year period) and spring-summer (biennial). In the 1980s, the most influential mode shifted from the NAM to the ADM, when the Pacific sector had low ice cover at a 1-year lag from the positive ADM, which was marked by low pressure over Siberia. In years when the spring-summer ADM was pronounced, it was responsible for distinct ice variability over the East Siberian-Laptev seas. The frequency separation in this study identifies the contributions of the ADM and spring-summer ADM. Effects of the latter are difficult to predict since it is intermittent and changes its sign biennially. The ADM and spring-summer ADM should be closely watched in relation to the on-going ice reduction in the Pacific-Siberian region. 


\subsection{Investigating Mechanisms Responsible for Arctic Sea Ice Minima Using PIOMAS}

On the basis of the above analyses, the +DA-derived wind forcing is the key to the ice minima. To further confirm such a key mechanism in the summers since 1995, in particular from 2007 to 2010, the PIOMAS (Zhang et al. 2008a) was used to simulate the sea ice and ocean circulation for the period 1978-2009 using daily NCEP forcing. Figure 4.5 shows the August SLP and wind anomalies from 2007 to 2010.

a

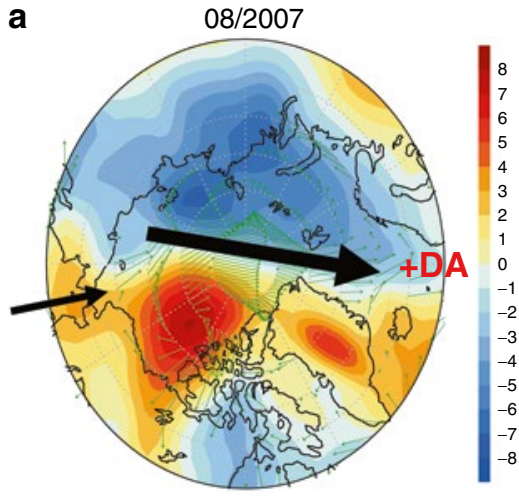

$\overrightarrow{3}$

C

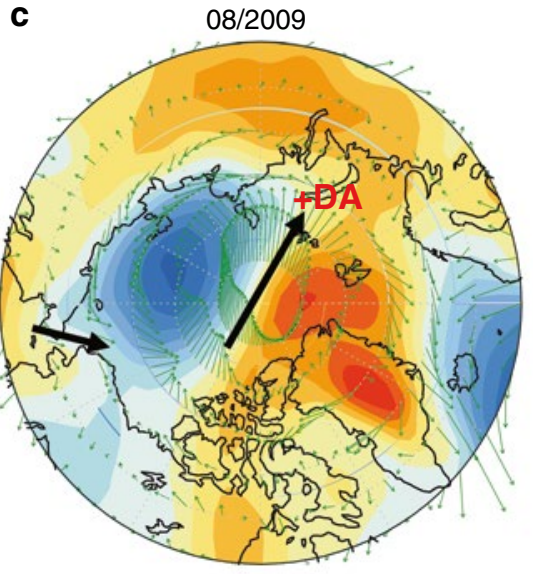

b

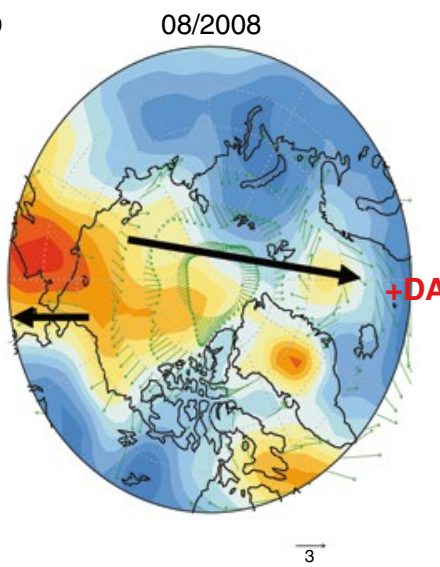

d

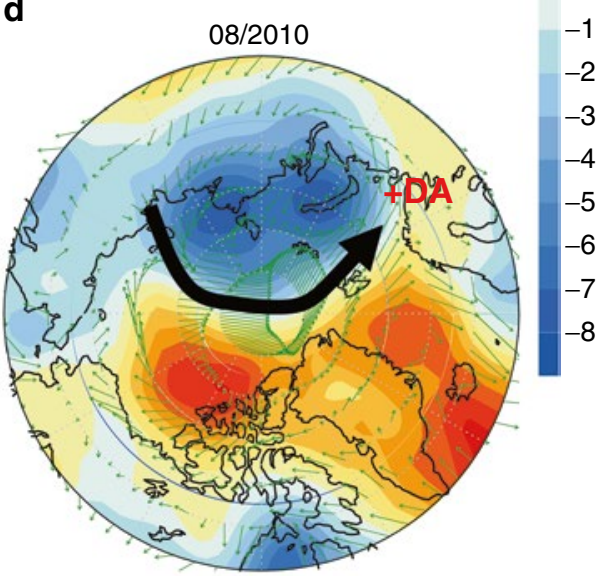

Wind Anomaly in $\mathrm{ms}^{-1} \underset{3}{\longrightarrow}$

Fig. 4.5 The 2007 (a), 2008 (b), 2009 (c), and 2010 (d) August SLP (shaded) and wind (vectors) anomalies relative to the 1948-2008 mean (data from NCEP Reanalysis). Red/blue indicates the positive/negative anomalies in SLP. The green arrows indicate the +DA-derived anomalous wind velocity (in $\mathrm{ms}^{-1}$ ). The DA-derived wind anomaly was the dominating driver for advecting sea ice toward the eastern Arctic, leading to the record minimum in the Arctic 


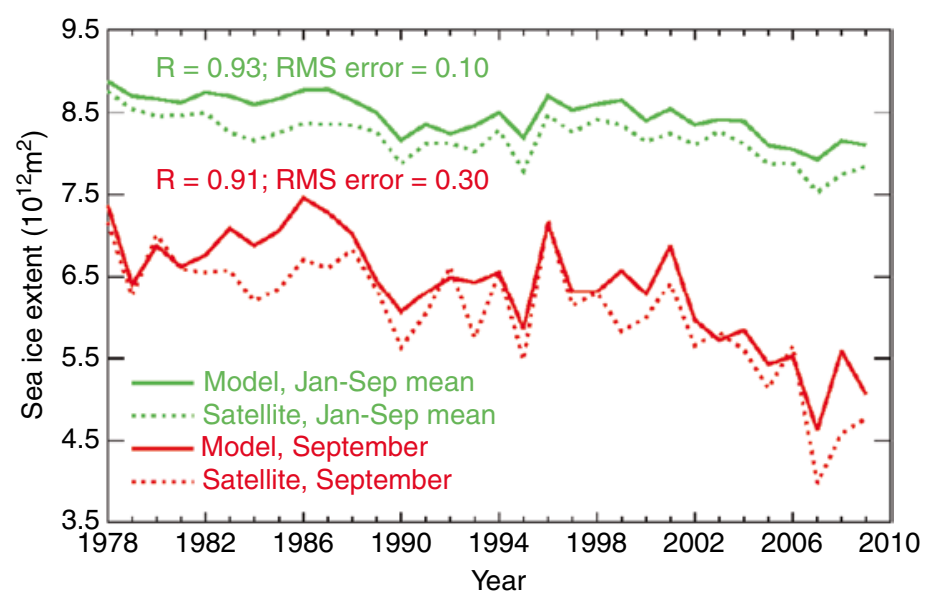

Fig. 4.6 Comparison between the PIOMAS-simulated and SSM/I-observed ice extent for the period 1978-2009

A common feature is that the DA was positive for all these summers. The differences are the magnitude and orientation of the DA-induced wind anomalies. Although the wind anomalies in 2007 were larger than 2008 in magnitude, the orientation for both years was more favorable for advecting sea ice out of the Arctic into the Nordic seas via the Fram Strait and the Barents Sea. Similarly, wind anomalies in 2007 and 2010 have a similar magnitude and both were larger than those in 2008 and 2009; nevertheless, the orientation of wind anomalies in 2010 was less favorable for advecting more ice out of the Arctic than 2007. The orientation of wind anomalies in 2009 was least favorable, since the primary ice advection was towards the Kara Sea.

Figure 4.6 shows that the simulated sea ice area compares well with the satellitemeasurements. The correlation between the observed and modeled time series of ice extent is 0.91 in September, while it is 0.93 for January-September. In particular, the model reproduces good agreement with summer ice minima in 1995, 2002, 2005, 2007, 2008, and 2009, though not for 1999 . The 2010 daily summer minimum ice extent $\left(4.810^{6} \mathrm{~km}^{2}\right)$ was just higher than in $2007\left(4.210^{6} \mathrm{~km}^{2}\right)$ and $2008\left(4.610^{6} \mathrm{~km}^{2}\right)$. This indicates that both the orientation and magnitude of the +DA are key for advecting of summer sea ice out of the Arctic.

The ice-ocean system, particularly the ice-ocean albedo feedback, is investigated in response to the strongest, most persistent (from winter to summer) DA event in 2007. To better understand the linkages between the rapid arctic sea ice retreat and the atmospheric changes during summer (July-September) 2007, it is helpful to examine how the changes are reflected in the NCEP/NCAR surface atmospheric forcing that is used to drive the model. The changes in SLP, surface winds, and surface air temperature (SAT) during summer 2007 are illustrated in Fig. 4.7. It compares the 2007 atmospheric conditions with those averaged over 2000-2006, a period of relatively low summer sea ice extent during the past three decades. Here, the 2000-2006 average is referred to as the "recent average" and the 


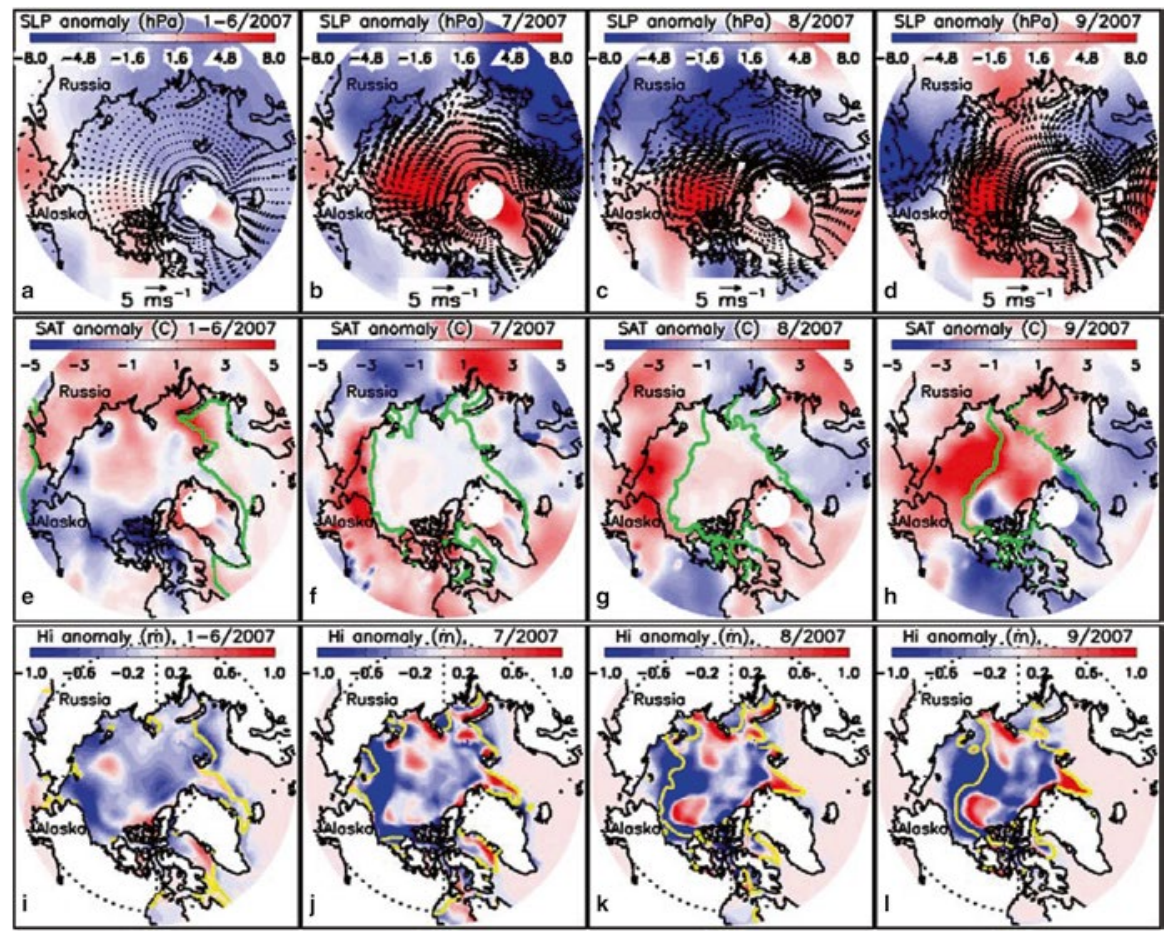

Fig. 4.7 Anomalies of the NCEP/NCAR reanalysis SLP and surface wind (a-d) and SAT (e-h); anomalies of simulated sea ice thickness (Hi) (i-l) In Figs. 4.7, 4.8 and 4.9, an anomaly is defined as the difference between the 2007 value and the 2000-2006 average. One of every 36 wind vectors is plotted in (a-d). The green line in ( $\mathbf{e}-\mathbf{h})$ represents satellite observed ice edge and yellow line in (i-l) model simulated ice edge of 2007

difference between a 2007 value and the recent average value is referred to as an "anomaly" (2007 minus the recent average) (Zhang et al. 2008a, b).

As shown in Fig. 4.7a, the Arctic +DA-like SLP and surface wind anomalies were small, but were gradually built up in the first half of 2007. In July, +DA-like SLP was considerably higher in much of the Arctic Basin and lower over a large area in Russia than the recent average (Fig. 4.7b). This is associated with stronger southerly winds in the northern Canada Basin and easterly winds along the East Siberia coast. In August and September, the well-defined +DA (Wang et al. 2009a) was developed: the high SLP anomalous center was mostly confined to the Canada Basin, and a low SLP anomalous center was located in the Barents Sea, producing stronger southerlies in the Pacific sector (Fig. 4.7c-d).

Similar to the SLP and wind anomalies, the arctic SAT anomaly was relatively small in the first half of 2007: SAT was slightly warmer in the central Arctic Basin and slightly cooler in the Chukchi and Beaufort seas compared to the 2000-2006 average (Fig. 4.7e). In July, the SAT anomaly increased significantly in the Chukchi Sea (Fig. 4.7f). In August and September the increase in SAT is most striking: the 


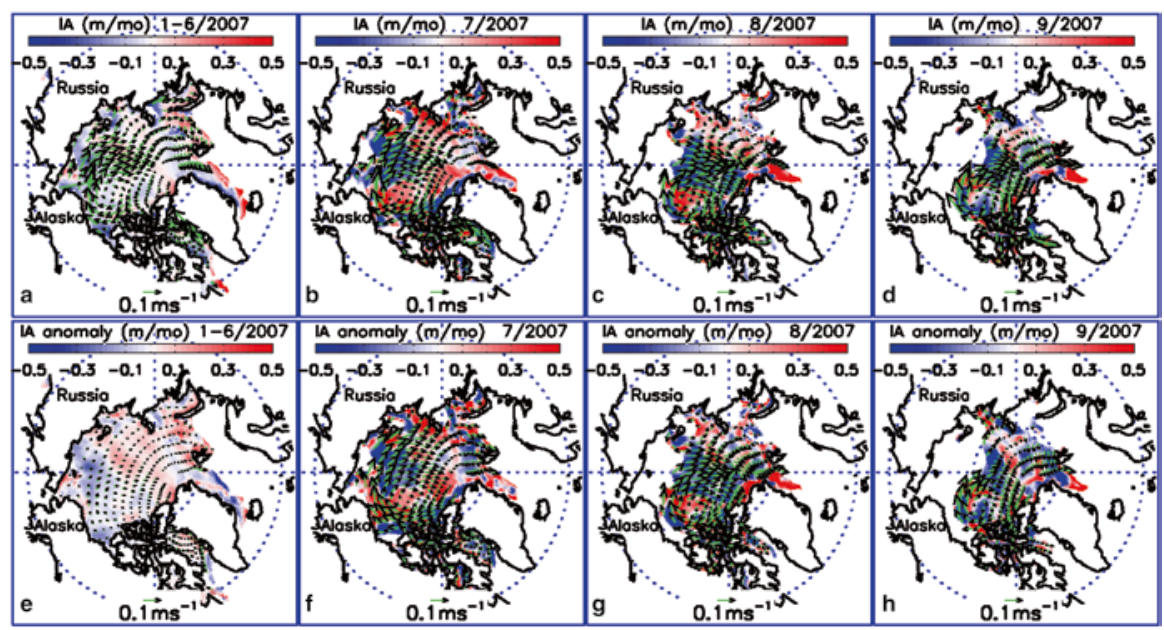

Fig. 4.8 PIOMAS-simulated ice motion (vectors) and ice advection (IA) (color contours) (a-d) and their anomalies (e-h). Note the difference between ice motion and ice advection. Ice motion is described by ice velocity and ice advection by ice mass convergence $[-\nabla \cdot(\mathbf{u} h)]$, where $\mathrm{u}$ is ice velocity and $\mathrm{h}$ is ice thickness. One of every 36 ice velocity vectors is plotted

SAT is up to $5{ }^{\circ} \mathrm{C}$ warmer than the recent average over much of the Pacific sector (Fig. 4.7g-h). However, in an area in the Canada Basin, the SAT in September 2007 was lower than the recent average (Fig. 4.7h). This SAT decrease is likely due to the air-ice interactions in that area where ice was thicker than the recent average. Sea ice was also thicker in August in that area (Fig. 4.7k); however, the SAT was not lowered (Fig. 4.7g).

What is the cause of the substantially-reduced ice cover in the Pacific sector during summer 2007? Zhang et al. (2008a, b) found, based on model results, that part $(-30 \%)$ of the anomalous reduction in ice extent mainly in the Pacific sector was due to the unusual ice advection, which was caused by the strengthened TDS and the DA-derived meridional wind anomalies. Ice motion in the Arctic Ocean is characterized by an anticyclonic Beaufort gyre and the TDS (Fig. 4.8a-d). In the first half of 2007, the SLP and wind anomalies were small (Fig. 4.7a), so changes in ice motion and changes in ice thickness due to ice advection were small in comparison to the 2000-2006 average (Fig. 4.8e). In July, there were stronger southerly winds in the northern Canada Basin (Fig. 4.7b). The ice motion responded to the winds with a much stronger TDS, so that there were considerable changes in ice thickness due to ice advection almost everywhere (Fig. 4.8b). In a large area of the Pacific sector, the reduction in ice thickness due to ice advection was up to $0.5 \mathrm{~m} / \mathrm{month}$ more than the recent average (Fig. 4.8f). In August and September, there were even stronger southerly winds in the Pacific sector (Fig. 4.7c-d), which further strengthened the ice motion and TDS (Fig. 4.8g-h). Thus, the Pacific sector continued to lose ice (Kwok 2008). Again, the reduction in ice thickness due to ice advection was up to $0.5 \mathrm{~m} / \mathrm{month}$ more than usual (Fig. $4.8 \mathrm{~g}-\mathrm{h}$ ). In other words, from July to September 2007, the unusual ice motion pattern drove so much ice into the Atlantic sector from 


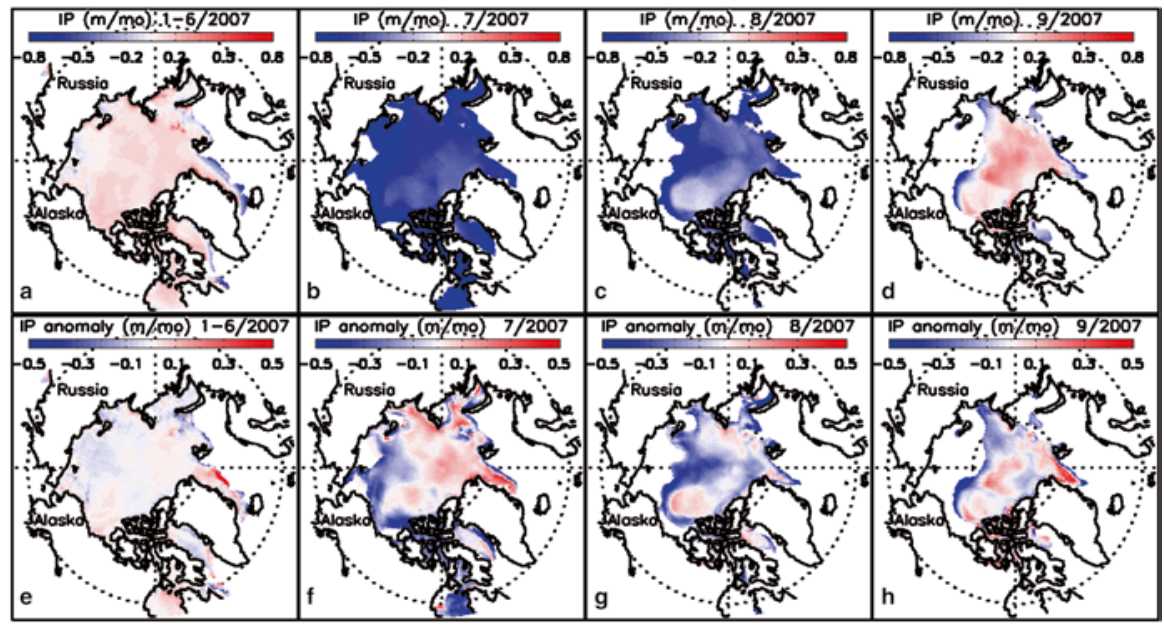

Fig. 4.9 PIOMAS-simulated ice production (IP) (a-d) and anomaly (e-h). Ice production is the net ice thermodynamic growth or decay due to surface atmospheric cooling/heating and oceanic heat transport, including ice-ocean albedo feedback contributed by the warm Bering water

the Pacific sector that the ice thickness in most of the Pacific sector was reduced by up to $1.5 \mathrm{~m}$ more than the recent average, leaving the Pacific sector with an unusually large area of thin ice and open water.

Major $(\sim 70 \%)$ anomalous reduction in ice extent in the Pacific sector during summer 2007 was due to reduced ice production or enhanced ice melting (Zhang et al. 2008a), which includes the ice-ocean albedo feedback (Wang et al. 2005b) and ice-cloud feedback (Ikeda et al. 2003). Ice production is the net ice thermodynamic growth or decay due to surface atmospheric cooling/heating and ocean heat transport. In summer, a decrease in ice production is equivalent to an increase in ice melting. Ice production was negative in July and August due to ice melting caused by atmospheric or oceanic heating (Fig. $4.9 \mathrm{~b}-\mathrm{c}$ ); it is generally positive in the JanuaryJune mean (Fig. 4.9a) and in September (Fig. 4.9d). In the first half of 2007, the ice production anomaly was generally small (Fig. 4.9e). In summer 2007, however, ice production decreased considerably in most of the Pacific sector (Fig. 4.9f-h) where a large reduction in ice thickness due to ice advection also occurred (Fig. 4.8b-d and f-h). This is because that the large reduction in ice thickness due to ice advection is associated with a large area of thin ice and open water, and thin ice and open water tend to allow more surface solar heating owing to the ice-albedo feedback (Wang et al. 2005b), leading to reduced ice production or enhanced ice melting (Zhang et al. 2008a; Lindsay et al. 2009). Therefore, the positive ice/ocean albedo feedback played a key role in the thermodynamic melting during the 2007 summer.

The changes in ice production represent the net effects of all the air-ice-ocean thermodynamic processes, which are also indirectly influenced by the oceanic and atmospheric dynamic forcings that enhance the thermodynamic melting, such as northward oceanic heat transport via the Bering Strait (Mizobata et al. 2010; 
Woodgate et al. 2010) and advection of warm air temperature from the south (Overland et al. 2008). Although the reduced ice production or enhanced ice melting in the Pacific sector during summer 2007 was dominated by intensified surface solar heating because of the ice-albedo feedback (Zhang et al. 2008a, b; Wang et al. 2005b), other thermodynamic processes also played a role via both direct and indirect contributions. For example, intensified solar heating also warmed the surface waters in the Pacific sector considerably (Steele et al. 2008; Perovich et al. 2008). The unusually warm surface waters in turn warmed the overlaying atmosphere, elevating summer SAT in the Pacific sector (Fig. 4.7f-h). The stronger southerly winds associated with + DA (Fig. 4.7b-c) may also contributed to increased SAT by bringing warm air from the south to the Arctic (Overland et al. 2008). An increase in SAT led to an increase in surface longwave radiation and turbulent heat fluxes, resulting in additional ice melting (Zhang et al. 2008a; Ikeda et al. 2003). Ocean circulation (advection) and its thermodynamic processes (heat transport via Bering Strait) also played a role in the reduced ice production or enhanced ice melting in the Pacific sector during summer 2007. Therefore, strictly speaking, the $70 \%$ of ice reduction due to thermodynamic processes should also include the indirect contribution by the oceanic and atmospheric dynamic forcings.

In summary, $\sim 30 \%$ of ice loss was due to wind advection (dynamic effect) directly associated with the DA, and $\sim 70 \%$ of ice loss was due to local melting (thermodynamic effect), which is caused by (1) anomalous warm water transport directly caused by the anomalous +DA-derived southerly wind, (2) anomalous high SAT directly advected by the +DA-driven southerly wind, and (3) positive ice-ocean albedo feedback by absorbing anomalous solar radiation. It is clear that the thermodynamic melting also implicitly includes the dynamic effect caused by the DA-derived wind anomaly. So, it was not a simple ice advection that pushed sea ice out of the Arctic to the Nordic Seas. Thus, Fram Strait ice transport must have better correlation to the DA index than the AO index, although the most melting is due to the local (in Pacific Arctic) thermodynamic effect/melting.

Therefore, it must be pointed out that it is impossible to separate the dynamic advection and thermodynamic melting of sea ice. These two processes highly interact and co-exist along with ice/ocean albedo feedback, in particular in the PAR during the + DA phase.

\subsection{Bering Strait Heat Transport and the DA}

Bering Strait volume and heat transport was continuously monitored since the late 1990s (Woodgate and Aagaard 2005; Woodgate et al. 2005, 2010; Mizobata et al. 2010). There are both seasonal ( $\mathrm{Hu}$ and Wang 2010) and interannual variations, which are connected to the Pacific-Arctic pressure head (Woodgate et al. 2005; Clement Kinney et al. 2009). However, what mechanisms are responsible to the recent increase of the volume and heat transport since 2004 on the interannual time scale is not well given. In particular, the 2007 heat transport reached a maximum 
(Wang et al. 2009a; Woodgate et al. 2010; Mizobata et al. 2010), coinciding with the all-time low in sea ice extent (Wang et al. 2009a). This implies a possible relationship between the volume and heat transport and the DA pattern.

The +DA not only drives sea ice from the western/Pacific Arctic to the eastern/ Atlantic Arctic via accelerating the TDS, but also promotes northward flow of warm Pacific water (Woodgate and Aagaard 2005) that contributes above-average heat transport from the Pacific, accelerating the drastic thinning of sea ice (Steele et al. 2004; Shimada et al. 2006; Zhang et al. 2008a). To confirm that the Pacific water heat transport increased in the 2000s, in particular in summer 2007, we calculated the heat transport through the eastern Bering Strait from 2000 to 2010 during the June-October ice free season. Figure 4.10 shows that since 2004, northward heat transport via the Bering Strait has an annual average of $12.14 \mathrm{TW}\left(1 \mathrm{TW}=10^{12} \mathrm{~W}\right.$ and $1 \mathrm{~W}=1 \mathrm{~J} \mathrm{~s}^{-1}$ ) from 2004 to 2007 , compared to the annual average of $6.4 \mathrm{TW}$ during 2000-2003, representing a $90 \%$ increase. The heat transport in 2007 (12.36 TW) had a $30.97 \%$ increase compared to the average of $9.27 \mathrm{TW}$ from 2000 to 2007. The heat transport from the Pacific Ocean has two important impacts, both direct and indirect, on sea ice in the western Arctic. The direct impact includes the bottom and lateral melting of sea ice when the warm Pacific water enters the Chukchi Sea, which enhances the melting via instant ice/ocean albedo feedback (see Sect. 4.4). The extreme event was the 2007 summer. The indirect impact involves a time-lag effect: the oceanic heat transport entering in the previous summer may survive winter (Shimada et al. 2006; Hu and Wang 2010) at the subsurface, which enhances the melting in the following spring and summer via ice/ ocean albedo feedback, which further amplifies the ice/ocean albedo process, leading to an early melting.

There is a possible relationship between the northward heat transport and the DA. Mizobata et al. (2010) showed that the regression model using the NNW-SSE wind component well reproduced the Bering Strait inflow. Figure 4.11 shows the scatter plot of heat transport against summer +DA indices from 2000 to 2009, since the heat transport data are available after 2000, while the data for 2010 heat transport was not completed (Fig. 4.10). Within the positive territory of summer DA index, the heat transport ramped up with positive DA index, with 2007 being the record high (Woodgate et al. 2010). The reason is that the orientation of the summer DA-induced anomalous wind maximum is almost parallel to the TDS and the Bering

Fig. 4.10 (a) Volume transport through the eastern Bering Strait for the period 1999-2010. Dotted lines indicate mean volume transport between 1999 and 2003 and between 2004 and 2007. Twoway bars close to $\mathrm{x}$-axis show period from June to October. Numbers above two-way bars show the integrating total volume transports from June to October through the entire eastern channel; (b) time series of averaged sea surface temperature (gray) and NCEP2-derived $330^{\circ}$ wind component (Wnd330ip) of sea surface wind (black); and (c) estimated heat transport through the eastern channel of Bering Strait from 1999 to 2010. Black bar means heat transport through Area 1, while white bar indicates heat transport through Area 2, which makes up the entire eastern Bering Strait channel (See Mizobata et al. 2010 for detail) 
a

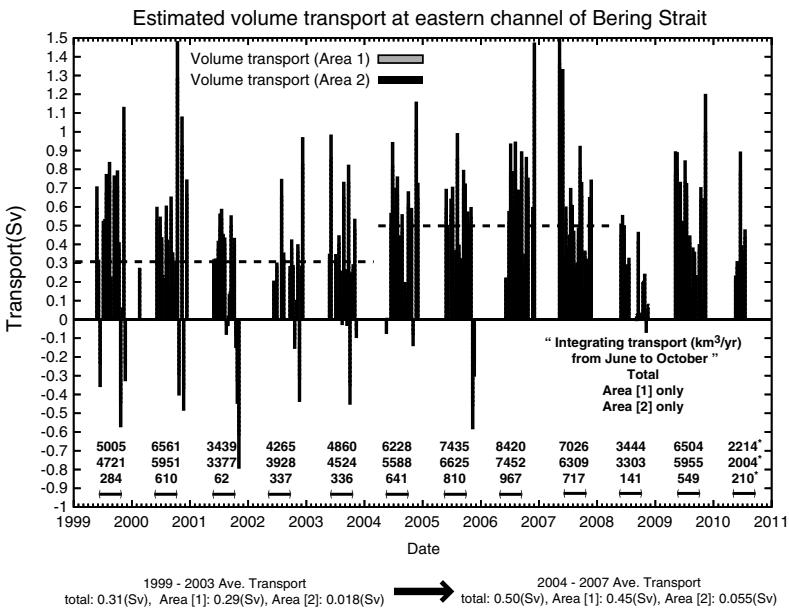

b
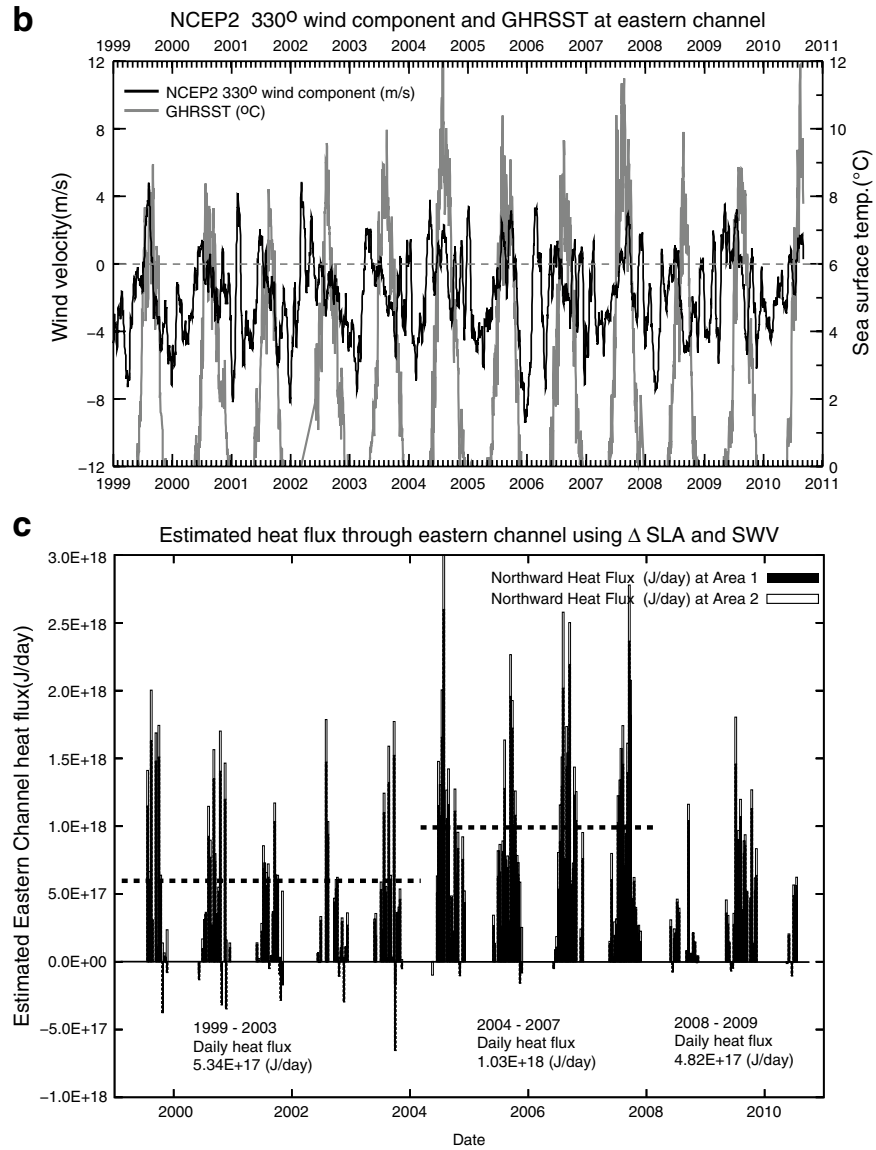


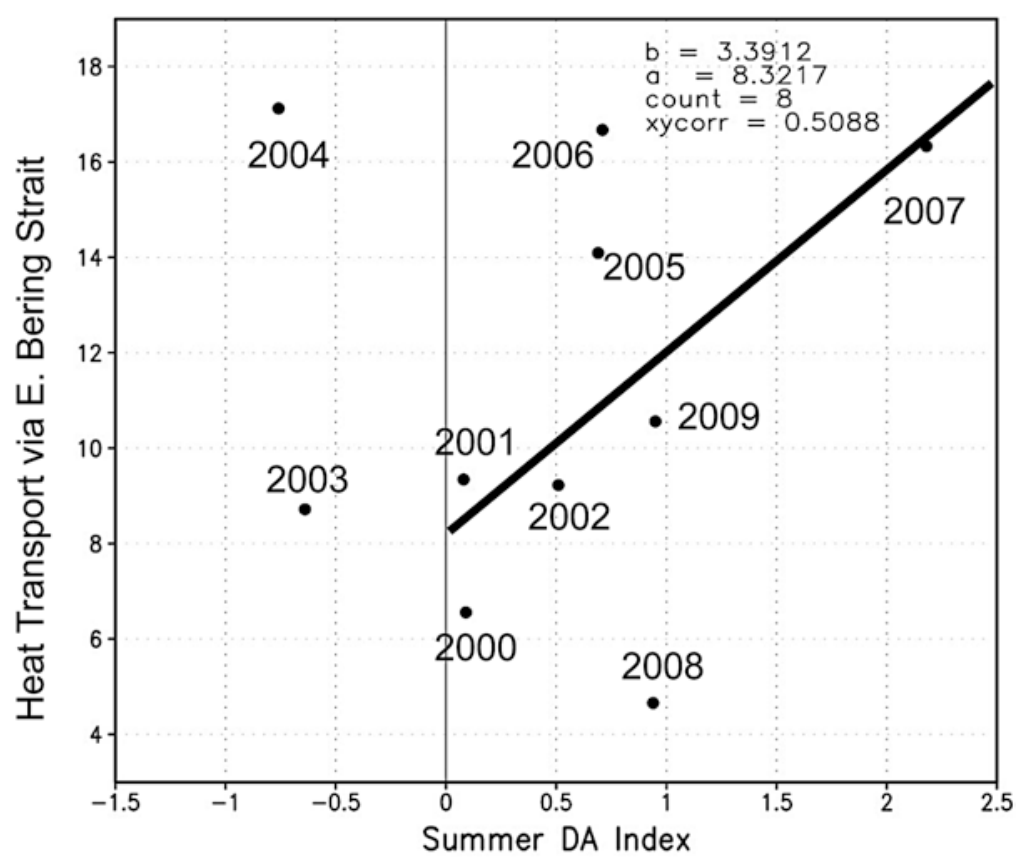

Fig. 4.11 Scatter plot between the summer DA index (x-axis) and northward heat transport via the eastern Bering Strait (y-axis) from 2000 to 2009. Units is in $10^{19} \mathrm{~J}_{\text {year }}^{-1}$ (June-October). The correlation between the heat transport and summer DA index is 0.51 , which is lower than 0.71 , the $95 \%$ significance level

Strait, effectively driving Bering warm water (i.e., volume transport and temperature anomalies; Fig. 4.10a, b) northward. In addition, a northward wind anomaly in the Bering Strait could enhance the heat transport to the Arctic Ocean in August 2007 (Fig. 4.10b). By contrast, the heat transport in August 2008 was only 3.52 TW, much smaller than the mean (9.27 TW) of 2000-2007 (Fig. 4.10c). The reduced heat transport in 2008 is likely due to a smaller magnitude of the +DA than that of 2007 (Fig. 4.5b). Another important reason is that over the Bering Strait, a southward local wind anomaly (Fig. $4.5 \mathrm{~b}$ and $4.10 \mathrm{~b}$ ) can significantly reduce the northward volume and heat transport in 2008. Therefore, the local N-S wind anomalies associated with basin-scale DA pattern should be included as a factor of influencing volume and heat transport (Mizobata et al. 2010). The correlation between the estimated heat transport and summer DA index is 0.51 (Fig. 4.11), although it is not significant at the $95 \%$ significance level (0.71) due to small number of the samples.

Although there is an association between the heat transport and +DA events, it needs further investigation using long-term measurements. Furthermore, in addition to large-scale and local atmospheric forcing, the orientation, bathymetry, and ocean boundary around the Bering Strait may be factors affecting the northward heat transport (Clement Kinney et al. 2009, 2014, this volume), which differs from the atmosphere that does not have a lateral boundary. 


\subsection{Modeling the Bering Sea Cold Pool Using CIOM}

Although summer sea ice in the PAR was experiencing abrupt decline since 1995 , the Bering Sea ice showed large interannual variability. This indicates the decoupling of the Arctic summer sea ice that includes multiple-year ice with winter Bering Sea ice (only seasonal ice), due to several factors. First, the Bering Shelf is very shallow, and thus has less memory to the oceanic heat content that varies from year to year; In other words, the year-to-year ice/ocean albedo feedback is negligible in the Bering Shelf. For example, the Bering heat transport, which flows via the Bering Shelf into the Chukchi Sea, caused a rapid decline of sea ice in the Chukchi Sea (Shimada et al. 2006), but had little influence on the winter sea ice in the Bering Shelf. Secondly, the Bering Sea is an open sea, while the Arctic Ocean is a mediterranean sea and its boundary constrains the sea ice extent in the winter. Thus, winter ice thickness (or volume) is a better variable for gauging climate change, although summer ice extent can be used for studies of climate variability (Wang and Ikeda 2001). Thirdly, Bering Sea ice is mainly controlled by atmospheric forcing (Zhang et al. 2010), which includes the competitive impacts of the $\mathrm{AO}$ and El Nino and Southern Oscillation (ENSO). By the contrast, Arctic sea ice is influenced both by the warm Atlantic inflow, the leading atmospheric modes such as the AO and the DA, and by the ice/ocean albedo feedback process (Ikeda et al. 2001; Wang et al. 2005b).

Although the Bering Shelf has relatively less memory of oceanic heat content in the previous winter to influence the winter sea ice in the following winter, compared to the Arctic Ocean, it has significant impacts on the local summer water temperature that can have significant impacts on local ecosystems and fisheries on the shelf (Grebmeier et al. 2010). An important feature on the Bering Shelf is the cold water (cold pool) mass on the bottom of the middle shelf (50-100 m isobaths) that persists throughout the summer (Takenouti and Ohtani 1974; Kinder and Schumacher 1981; Wyllie-Echeverria 1995). The cold water was even observed in late September and early October (Kinder and Schumacher 1981). Hu and Wang (2010) investigate the seasonal change of the cold pool using the CIOM, and found that the largest vertical temperature difference, surface minus bottom, is $>7{ }^{\circ} \mathrm{C}$ in the middle domain, suggesting that the cool pool survives the summer. The cold pool extends from the Gulf of Anadyr in the west with a temperature of $<-1.0{ }^{\circ} \mathrm{C}$ (Hufford and Husby 1972) to a variable eastern boundary over the southeastern shelf with a temperature of $2{ }^{\circ} \mathrm{C}$ (Maeda et al. 1967). The extent and volume of the cold pool vary based on the past winter's meteorological and oceanic (convection) conditions. The minimum annual extent can reach eastward about $170^{\circ} \mathrm{W}$, while the maximum extent can cover Bristol Bay (Fig. 4.12a).

The existence of the cold pool in summer is important not only to the physical environment, but also to marine ecosystems. The cold pool is an ideal habitat to some arctic cold water species such as arctic cod, and acts as a barrier to certain species such as walleye pollock since they prefer water temperature warmer than $2{ }^{\circ} \mathrm{C}$. When the volume and extent of the cold pool change from year to year, 

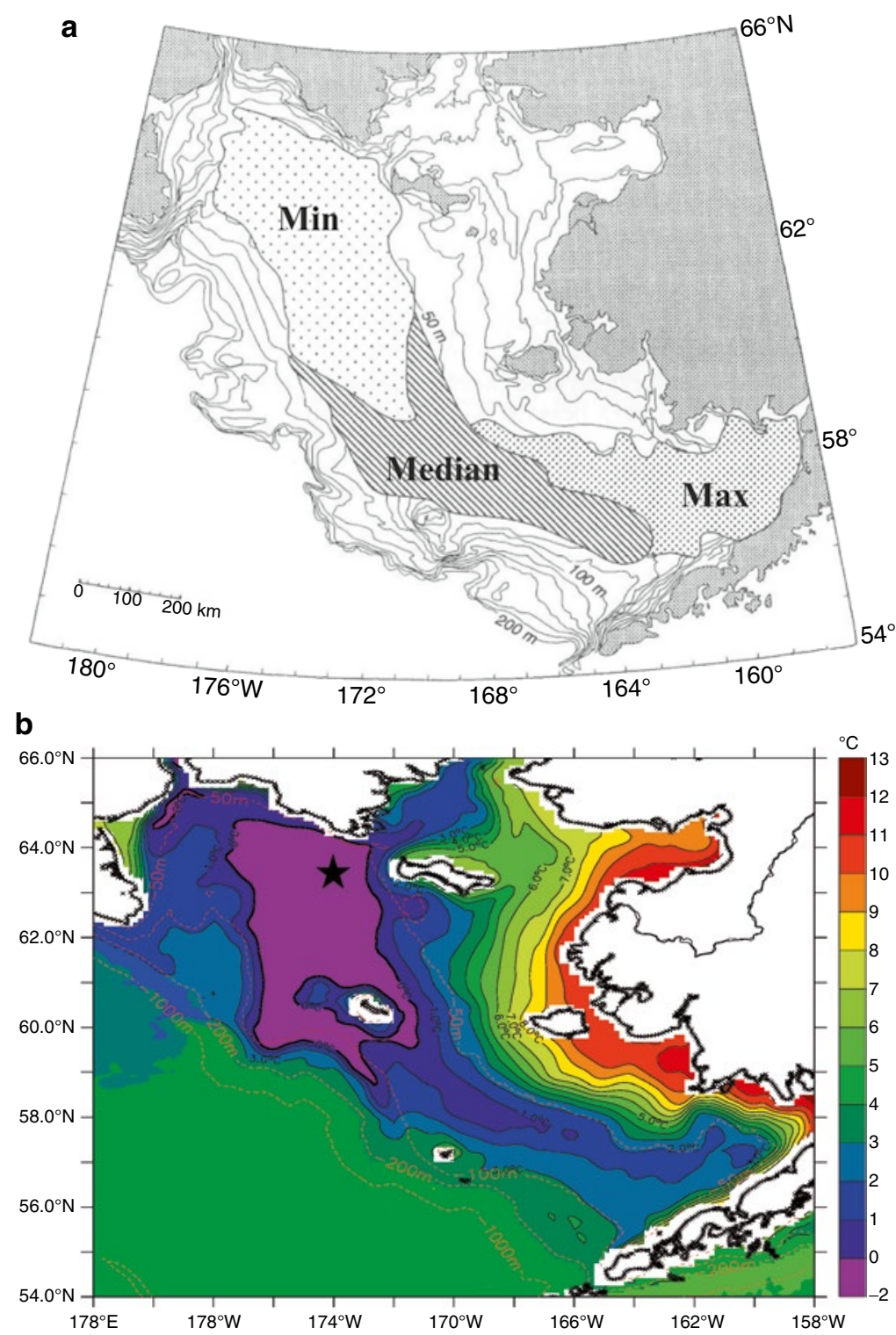

Fig. 4.12 (a) The schematic diagram for the cold pool extent based on historical measurements and knowledge. The sparse dots, strips, and dense dots represent the minimal, median, and maximal extent of the cold pool, respectively, and (b) the CIOM-simulated summer bottom water temperature (b). The star indicates the location of $\left(173.5^{\circ} \mathrm{W}, 63.7^{\circ} \mathrm{N}\right)$ used in Fig. 4.13 


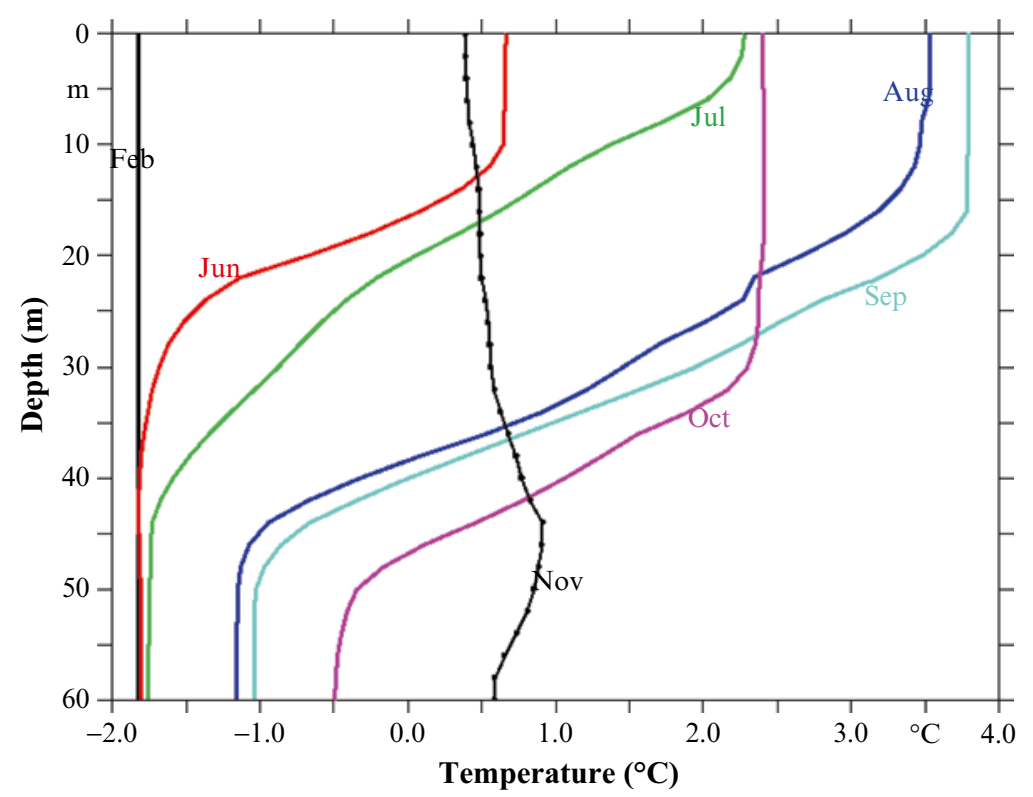

Fig. 4.13 The CIOM-simulated monthly-averaged vertical temperature structure at a northeastern location (see Fig. 4.12b) on the Bering shelf

the population of local species may increase or decrease accordingly to their preference. Thus, the cold pool can affect biomass growth rate and distributions on the Bering Sea shelf.

The summer (August-averaged) cold pool is reproduced by the CIOM(Fig. 4.12b). The cold water lies on the middle shelf between the 50-100 m isobaths, and it may reach the shelfbreak (200-m isobaths) in the western shelf break. The bottom temperature increases gradually from the 50-m isobath to the Alaskan coast. The maximum temperature reaches $11^{\circ} \mathrm{C}$ near Norton Sound coast. The basin water at $200 \mathrm{~m}$ is basically $>3{ }^{\circ} \mathrm{C}$. The minimum bottom temperature in the middle of the southeastern shelf is $>0{ }^{\circ} \mathrm{C}$, compared to the northwestern shelf bottom water of $<0^{\circ} \mathrm{C}$.

A vertically stable temperature structure inhibits convective heat transfer from surface layer to bottom layer (Hu and Wang 2010). Figure 4.13 shows the progression of monthly-averaged vertical temperature profiles in the cold pool region (see location in Fig. 4.12b). The winter temperature structure is vertically homogeneous (November to March), indicating the surface-to-bottom convection and production of winter shelf water. As solar radiation increases in March, the surface temperature rapidly increases. The surface stratification forms at the upper $10 \mathrm{~m}$ layer in June, and increases from June to July due to solar heating and sea ice melting, reaching a strongest stratification in July. The SST gradually increases from August to September, reaching the maximum in September. Then, the mixed-layer starts to deepen due to cooling in September. From October to November, the vertical stratification rapidly disappears during strong wind mixing and cooling, becoming vertical homogeneous in December. 


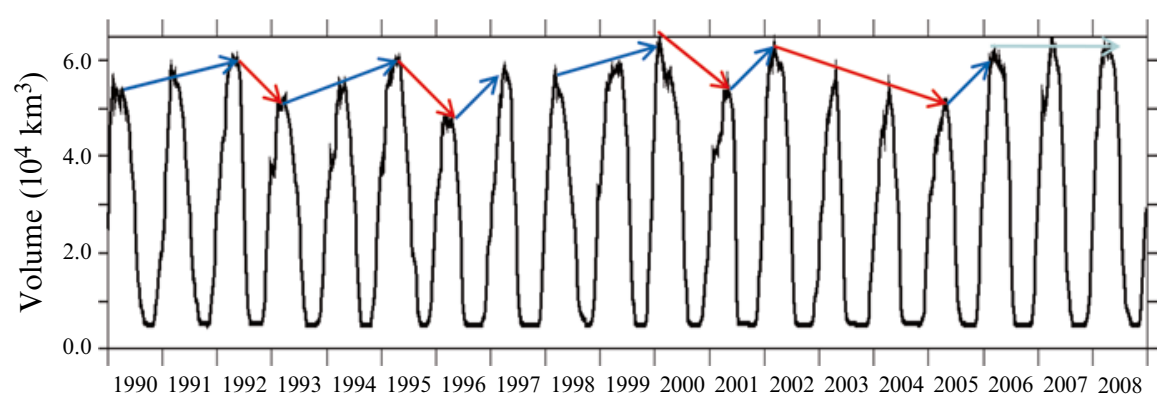

Fig. 4.14 The CIOM-simulated time series of the cold pool volume from 1990 to 2008 (units in $10^{4} \mathrm{~km}^{3}$ ). The blue (red) arrows indicate the increase (decrease) of the cold pool volume, which corresponds to the cooling (warming) winter

It is noted that the bottom cold water, which forms during winter seasons, can survive the summer months (Fig. 4.13). At this specific northern location, the bottom water is as cold as $-1{ }^{\circ} \mathrm{C}$, with a well-defined stratification in August and September. Therefore, the cold pool water mass is a seasonal phenomenon on the Bering shelf, which has significant impacts on regional ecosystems and fisheries distribution.

The CIOM, driven with daily atmospheric forcing, was used to calculate instantaneous cold pool volume for years 1990-2008 according to the formula of $\mathrm{Hu}$ and Wang (2010)

$$
\text { Volume }_{-C P}(t)=\sum_{i, j, k=1}^{N, M, K} \Delta x_{i, j, k} \Delta y_{i, j, k} \Delta z_{i, j, k} \text {, if } \mathrm{T}(\mathrm{x}, \mathrm{y}, \mathrm{z}, \mathrm{t}) \leq 2{ }^{\circ} \mathrm{C} \text {. }
$$

Figure 4.14 shows the interannual variability of the cold pool volume, which is an indicator of year-to-year water property change induced by atmospheric forcing (Zhang et al. 2010; Overland et al. 2012). The colder the atmospheric temperature and the stronger the northerly winds, the stronger the vertical convection, leading to a larger cold pool extent and volume. The cold pool had a high extent/volume in 1991, 1992, 1995, 2000, 2002, 2006-2008, and had a low extent/volume in 1993, 1996, 2001, and 2005. The year-to-year changes in volume of the cold pool significantly impact or modify the distribution of marine ecosystems, since temperature-sensitive species are distributed according to their preference of habitat environment.

It is noted that there are two processes involving the year-to-year change in the cold pool volume. The first one is the abrupt change of atmospheric forcing. For instance, an abrupt decrease in the volume in 1992-1993, 1995-1996, and 2000 2001 reflects the abrupt change in atmospheric conditions with warming and weak northerly winds. The abrupt increase in volume occurred in 1996-1997, 2001-2002, and 2005-2006, indicating the sudden cooling and increase in northerly wind anomalies over the Bering Sea. The second process is the water temperature 
memory effect. During an increased progression in cold pool volume, it often takes 3 years to reach the maximum, such as in 1990-1992, 1993-1995, and 1998-2000, indicating the memory of water heat storage. However, very often it only takes 1 year to detect the abrupt increase in cold pool volume such as in 1996-1997, 2000-2001, and 2005-2006, indicating that a significant change of atmospheric forcing is more important than the heat memory in the Bering Shelf (Overland et al. 2012). The longest decrease in cold pool volume occurred during 2002-2005, followed by the three straight high years from 2006 to 2008, indicating a cold phase in the region, consistent with the cooling of the water temperature in the M2 site in the southeastern Bering shelf (see Fig. 4.5 of Overland et al. 2014, this volume). The persistency of the large cold pool volume during 2006-2008 should have significant impacts on ecosystems and fisheries in the coming years, which should be closely monitored.

\subsection{Modeling Landfast Ice in the Beaufort-Chukchi Seas Using CIOM}

Landfast ice along the coastline of the PAR plays an important role as a biologically productive habitat and transportation corridor; it also provides important protection to the shoreline and coastal installations (Eicken et al. 2009). However, at the present time it is not clear how the diminishing Arctic summer sea ice and the reduction in multi-year ice extent (Maslanik et al. 2011) have impacted the seasonal cycle and distribution of landfast ice. Thus, while the seasonal and interannual variability of the landfast ice in a diminishing sea ice scenario in the PAR are an important emerging topic; evidence of such variability is somewhat limited. This is largely due to the temporally limited availability of synthetic aperture radar imagery required for accurate assessments of landfast ice extent (Mahoney et al. 2007). Model simulations with coupled ice-ocean models can hence provide insight into longer-term variations on time-scales of decades, although the modeling of landfast ice at these scales is in its infancy (e.g., König Beatty and Holland 2010).

Landfast ice along the Chukchi and Beaufort coast is a seasonal phenomenon with interannual variability (Eicken et al. 2006; Mahoney et al. 2007). It is a great challenge for any coupled ice-ocean model to capture the dynamic and thermodynamic features of landfast ice, since many factors can affect the formation, anchoring, and melting of landfast ice, such as wind forcing, ocean currents, coastal topography and bathymetry, and model resolution. To this end, a 3.8-km resolution CIOM (Wang et al. 2003, 2008; Jin et al. 2008) was used to investigate the seasonal and interannual variability of landfast ice in the Chukchi and Beaufort seas.

There are two approaches to distinguish landfast ice from pack ice in a model. One way is to define landfast ice by an ice velocity criterion that considers ice stationary below a given velocity threshold. In this study, if both the absolute ice velocity is less than $4 \mathrm{~cm} / \mathrm{s}$, and the water depths are less than $35 \mathrm{~m}$, then grid cells are designated as landfast ice. The second, prescriptive method stipulates that 
Fig. 4.15 The CIOM-

simulated June climatological sea ice concentration (a, from 0 to 1 ) with sea ice velocity vectors superimposed (vector size indicates speed in $\left.\mathrm{ms}^{-1}\right)$, and sea ice thickness $(\mathbf{b}$, in meters). Landfast ice remains attached along the Beaufort Sea coast. The green (orange) arrows denote the ocean surface current (ice flow)
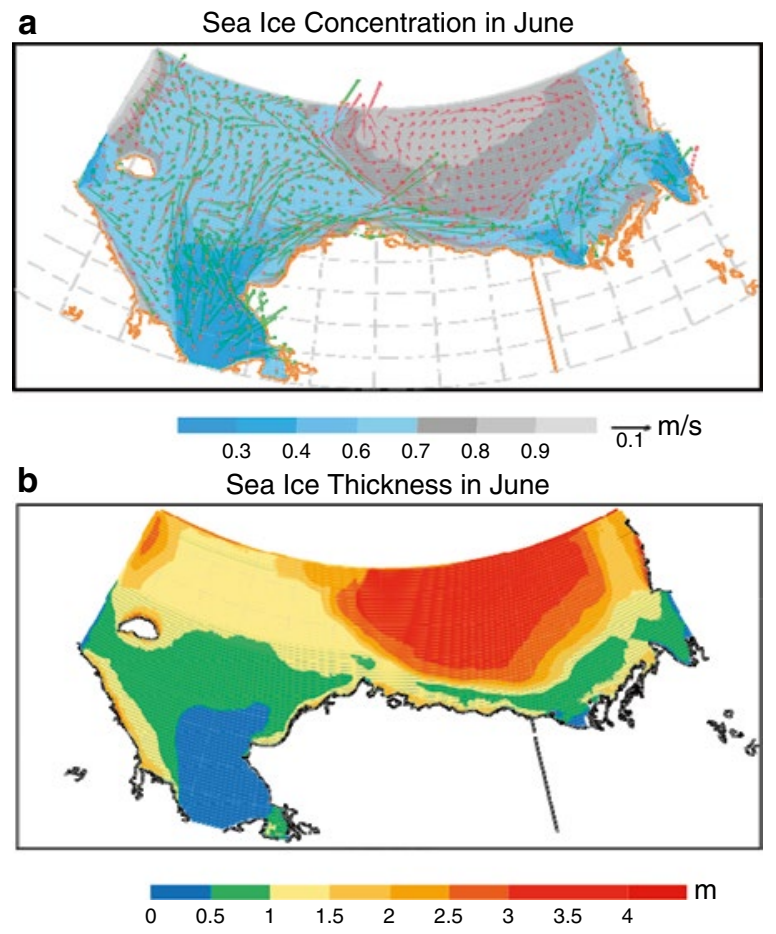

during the simulation, the wind stress and ice velocity are set to zero shoreward of the $35 \mathrm{~m}$ isobaths, roughly corresponding to the extent of landfast ice. This method is widely used in Baltic Sea ice simulations (Haapala et al. 2001; Meier 2002a, b), which may not be capable of representing spatial and interannual or seasonal landfast ice extent.

Figure 4.15 shows the CIOM-simulated climatology of June sea ice concentration (SIC) and thickness using the daily NCEP forcing for the period 1990-2007. The SIC map (Fig. 4.15a) clearly shows what corresponds to simulated landfast ice attaching to the Alaskan Beaufort and Chukchi coast during the melt season as ice of high concentration. During spring, surface melting commences nearshore, but ice concentration first decreases offshore as a result of complete melting and removal of thinner offshore ice in areas of higher open water concentrations that promote absorption of solar heat. This is also reflected in the small magnitude of ice velocity vectors superimposed on ice concentration in Fig. 4.15a; nevertheless, since landfast ice is not modelled explicitly, small residual velocities remain in some areas of effective landfast ice. However, at the same time, the strong contrast between stationary landfast ice and highly mobile ice just offshore from the landfast ice edge appears to be well captured. Even in mid-July, Beaufort landfast ice remains, not melting completely until the end of the month, depending on weather (SAT and wind direction) conditions. 

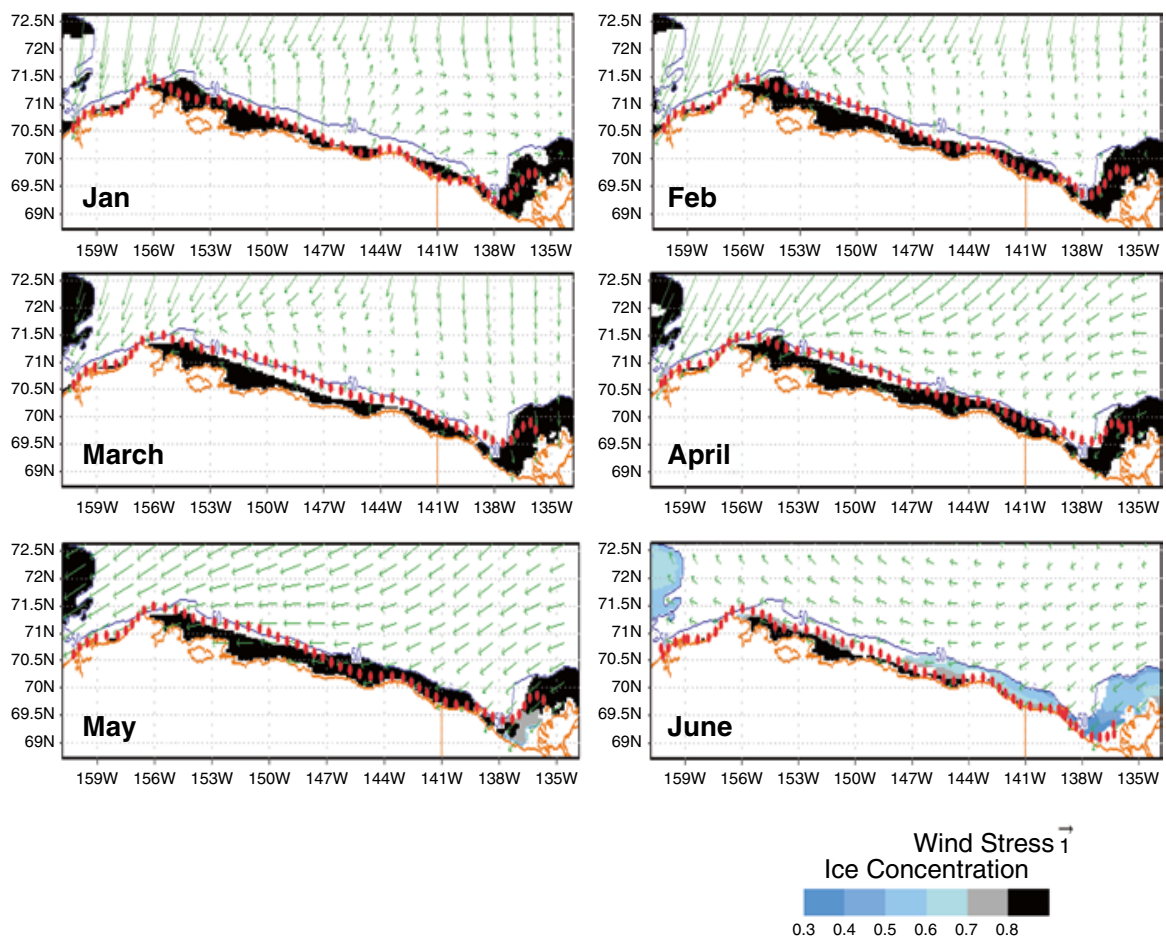

Fig. 4.16 The CIOM-simulated January-June climatological landfast ice extent (from 1990 to 2009, black shaded) compared to landfast ice edge locations derived from synthetic aperture radar satellite data (red dots) averaged for the period 1996-2004. Green vectors: Wind stress in $10^{-5} \mathrm{~N} \mathrm{~m}^{-2}$

The simulated sea ice thickness map (Fig. 4.15b) in June shows some contrast in landfast ice thickness along the Beaufort and Chukchi coast $(\sim 1.5 \mathrm{~m})$ and thinner offshore $(<1 \mathrm{~m})$ ice. Since the model is not explicitly simulating processes that contribute to landfast ice stabilization, in particular grounding of pressure ridges (Mahoney et al. 2007), other processes represented in the model can explain the formation and maintenance of landfast ice. These include the following factors based on a series of controlled sensitivity experiments in Wang et al. (2010): (1) an onshore northeast wind due to the Beaufort high pressure system, (2) the eastward ACC and Beaufort Slope Current with its right-turning force due to the Coriolis effect, which advect the warmer Bering water, (3) high resolution topography and bathymetry constraining ice motion in the coastal regions, and (4) sea ice advection. However, these model-inherent factors that help keep landfast ice in place in nature deserve further investigation.

Figure 4.16 shows the climatology (1990-2007) of the simulated landfast ice that was compared to observed landfast ice extents obtained from synthetic aperture radar satellite data for the period 1996-2004 (Eicken et al. 2006; Mahoney et al. 2007). In the model, landfast ice starts to form in autumn due to the Beaufort Gyre and 
anticyclonic winds induced by the Beaufort High, both of which push sea ice toward the Alaskan Beaufort coast, coupled with the thermal growth of sea ice along the shore (Wang et al. 2010). When sea ice completely covers the entire Arctic from December on, landfast ice is attached to shore, while pack ice offshore still moves with the ocean surface current and wind forcing. During the period of complete ice cover, the radar satellite data indicate quasi-stationary landfast ice with a clearly delineated boundary between pack ice and landfast ice (anchored to the bottom and attached to shore with the velocity almost being zero), while the CIOM-simulated landfast ice still exhibits small movement, since the sea ice produced in CIOM is not resolving the anchoring of grounded pressure ridge keels that stabilize the landfast ice. Thus, more research is required to improve the representation of ice dynamics in coastal regions and landfast ice processes by formulating and including the relevant ice anchoring mechanisms in the model.

The CIOM-simulated landfast ice is generally consistent with landfast ice extent derived from satellite data. The CIOM reproduces the landfast ice boundary in January and February very well. However the model reproduces less landfast ice than the measured boundary in March. During April, the melting season, the CIOM reproduces landfast ice reasonably well in general, but reproduces less ice from $147^{\circ}$ to $152^{\circ} \mathrm{W}$. In May, CIOM reproduces more landfast ice between $140^{\circ}$ and $147^{\circ} \mathrm{W}$. In June, the model simulation compares very well with the measurement.

To investigate the interannual variability of the landfast ice, we first constructed the seasonal cycle of landfast ice area based on those grid cells conforming with the ice velocity criterion described above and along the coast with depth of less than $30 \mathrm{~m}$ within $160^{\circ} \mathrm{W}-134^{\circ} \mathrm{W}$ for the period of $1990-2007$ (Fig. 4.17a). Three characteristics are apparent: (1) landfast ice exhibits a uniform extent indicative of overall stability of the ice cover from January through April with a maximum in February; (2) the largest variability (i.e., standard deviation) occurs in June and November, during the peak of the melt (decay) and freeze-up (formation) seasons, respectively; and (3) there is no landfast ice in August and September. Figure 4.17b shows the year-to-year variability of the landfast ice. One striking feature is that the landfast ice formed earlier and melted later before 1998, while since then the duration of the landfast ice season has shortened significantly. This is consistent with the increase in Bering Strait heat transport since 2001 (Woodgate et al. 2010), in particular since 2004 during which both temperature and volume transport increased (Fig. 4.10c). In the spring of 2007, landfast ice decayed more rapidly than in other years, since the + DA-derived wind anomaly was directed offshore (i.e. northward) (Wang et al. 2009a), in addition to other forcings such as maximum Bering Strait heat transport (Woodgate et al. 2010; Mizobata et al. 2010), and ice/ocean and cloud albedo feedbacks (Ikeda et al. 2003; Wang et al. 2005b), leading to thinner pack ice. Figure $4.17 \mathrm{c}$ shows the time series of landfast ice area anomalies for 1990-2007. It is clear from the figure that from 1990 through 1997, positive anomalies dominated, while since then Beaufort and Chukchi Sea landfast ice extent was characterized by negative anomalies. As evident from Fig. 4.17b, these anomalies are not due to reductions in maximum extent, but rather driven by shifts in the seasonality of the landfast ice. This finding is in line with observations 

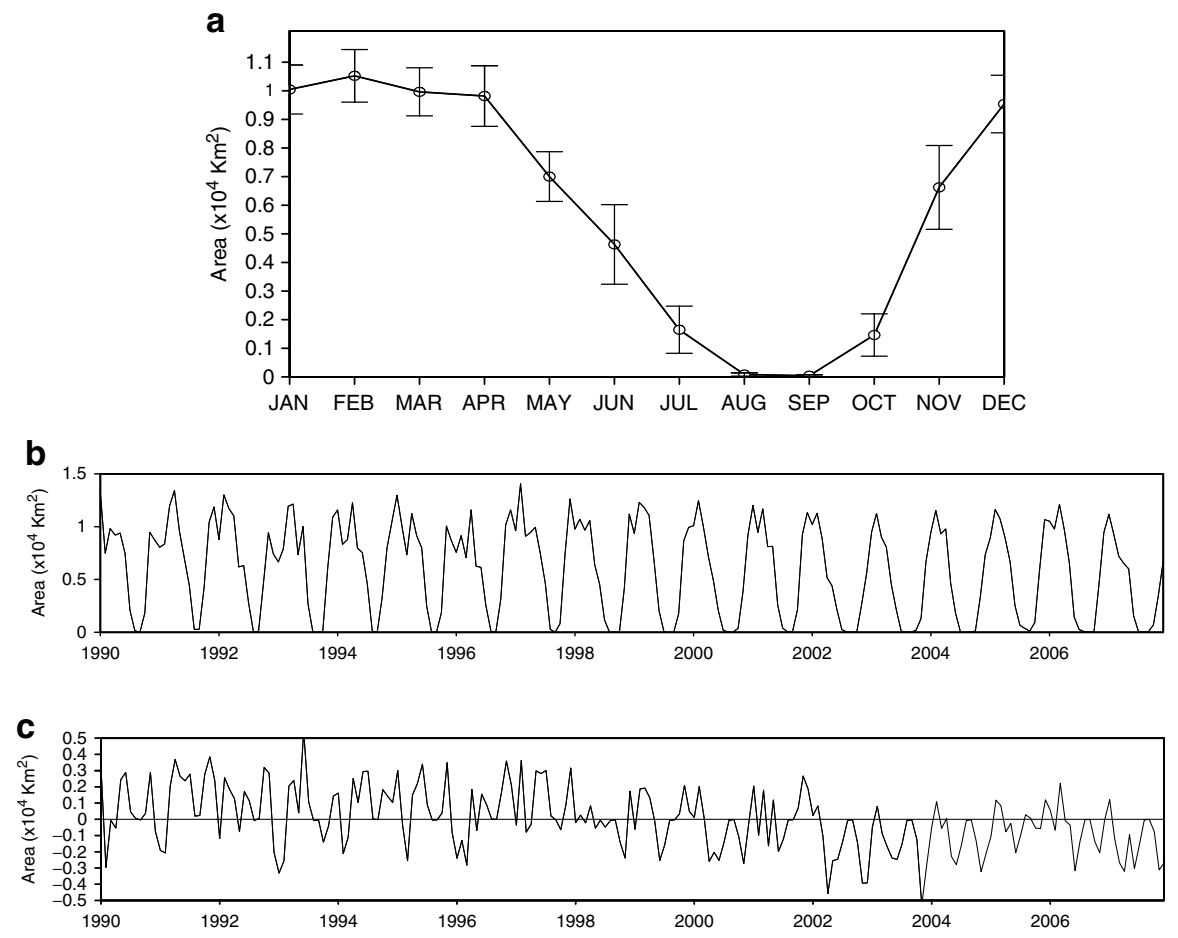

Fig. 4.17 (a) Modeled seasonal climatology of landfast ice area with standard (one) deviations (vertical bars) for the period of 1990-2007; (b) modeled monthly landfast ice area from 1990 to 2007; and (c) modeled monthly landfast ice area anomalies from 1990 to 2007. The landfast ice area is calculated with ice concentration being greater than 0.6 within the Beaufort and Chukchi coastal region between $160^{\circ} \mathrm{W}$ and $134^{\circ} \mathrm{W}$

by Mahoney et al. (2007) and points to the importance of decadal-scale variations in landfast ice extent. A more detailed analysis of model simulations over a longer time period, drawing on available remote-sensing and in situ observations, is required to elucidate the role of secular change and regional warming in explaining such changes in landfast ice extent.

\subsection{Possible Air-Ice-Sea Feedback Loops in the Western Arctic}

In the Pacific Arctic, from the Bering Sea to the Arctic Ocean, there is a regional feedback loop among the atmosphere, sea ice, and ocean (Wang et al. 2005b). The recent increase in Bering Sea heat transport into the Chukchi Sea since 2000 (Woodgate et al. 2010; Mizobata et al. 2010) is closely related to the continuous ice 


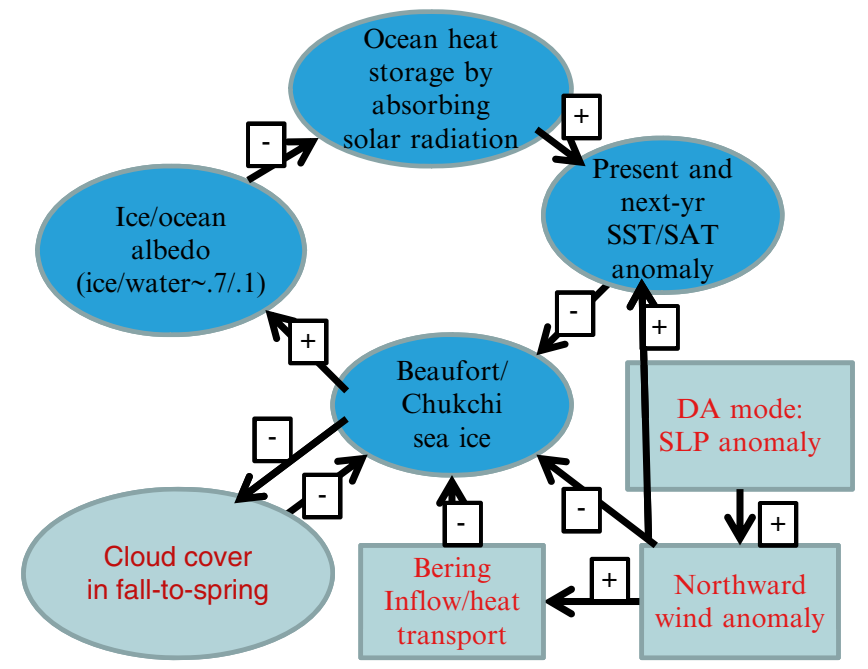

Fig. 4.18 A proposed possible positive air-ice-sea feedback in the western Pacific Arctic Region. $+/-$ indicates positive/negative feedback. Negative feedback between ice cover anomaly and clouds is shown on the lower left corner. Less ice cover (or more open water) leads to more clouds cover in fall to spring, which further results in less ice cover due to reduction of long-wave radiation to the upper atmosphere (or space). The long-wave radiation is reflected back to the ice-ocean surface, leading to higher SAT/SST anomalies and less ice cover. The +DA can accelerate and amplify the existing ice/ocean albedo feedback

decline in the Western Pacific (Shimada et al. 2006). Although a well-known positive ice/ocean albedo feedback is in play in general (Wang et al. 2005b), a conceptual connection in the PAR was not established.

Figure 4.18 depicts a possible regional interaction among the atmosphere, sea ice, and the ocean. The +DA-induced wind anomaly enhances the northward transport of the Bering warm water, i.e., heat transport (Mizobata et al. 2010), and also drives sea ice from the Western Arctic to the Eastern Arctic (Wang et al. 2009a; Ikeda 2012) via strengthening of the TDS (Comiso et al. 2008). The oceanic heat transport entering the Chukchi Sea instantly enhances the melting of sea ice, seasonal positive ice/ocean albedo feedback, and increases the local heat storage, as discussed in Sect. 4.4 and by Zhang et al. (2008a, b). Then, the excessive heat will accelerate the melting process during the following winter and spring, and slow down the freezing in the following autumn. In the following summer, more open water absorbs more solar radiation (since the ice and ocean albedos are $\sim 0.7$ and 0.1 , respectively) and the heat storage increases, which is the well known positive ice/ ocean albedo feedback. The heat stored in the upper ocean layer will be present in the following autumn and winter, increasing the SST and SAT, delaying the freezing in the autumn and thinning the sea ice in the winter. The thin ice in winter will lead to early break-up in the following spring, and to more open water in the following summer, absorbing and storing more heat from solar radiation. 
In summary, +DA-induced northward wind anomaly has two important impacts on the Western Arctic ice-ocean-ecosystems. The first is a direct, seasonal impact. The northward wind not only drives sea ice away from the Western Arctic to the Eastern Arctic, but also enhances the inflow of the warm Bering water into the Chukchi Sea (Zhang et al. 2008a, b; and see discussion in Sect. 4.4), instantly melting sea ice in the Chukchi Sea and increasing the SST and SAT (Zhang et al. 2008a, b; and see discussion in Sect. 4.4). The seasonal ice/ocean albedo feedback also accelerates ice melting in the Chukchi Sea. The second impact is an indirect, year-to-year cumulative impact. Since the heat transport advected into the Chukchi Sea increases, the excessive heat can be stored in the water column and often can survive the winter. This would lead to the positive ice/ocean albedo feedback in the following year, as depicted in Fig. 4.18 and discussed above.

As suggested by Ikeda et al. (2003), cloud data collected over the Arctic Basin have proved that a cloud increase during the period 1960-1990 made a significant contribution to a reduction in net upward longwave radiation. The importance of clouds applies also to the decadal ice cover variability. The heat transport trend was estimated to be a linear increase in the annual flux to the ice-ocean system at $10 \mathrm{Wm}^{-2}$ in the 30-year period. It is a logical expectation that part of the increase in autumn-to-winter cloud cover is in turn due to increased evaporation from the increased open water area. Thus, an ice-cloud feedback may enhance the ice cover reduction (Fig. 4.18, see the lower left corner). The cloud cover changes over the Arctic induce thermodynamic effects comparable with the albedo reduction caused by the ice reduction. Since Arctic clouds are not convincingly simulated in doubled carbon dioxide experiments, further work on cloud parameterization, and subsequent analysis of model output, are highly recommended.

\subsection{Summary}

Based on the above investigations of several emerging climate-related ice-ocean processes, the following conclusions can be drawn:

1. Although the ratio of the AO to the DA is about $4: 1$ in terms of total variance of SLP (i.e., surface wind), the DA-induced wind anomaly is meridional, compared to the zonal wind anomalies induced by the AO. Furthermore, the + DA-induced maximum wind anomaly is nearly parallel to the TDS, thus accelerating the TDS and effectively enhancing ice export. There is seasonal variation of the DA: (1) the summer and autumn DA intensity (or variance, i.e., wind anomaly) is larger than the winter and spring, and (2) the orientation of the DA-induced wind anomaly in spring and summer is more parallel to the TDS than the winter and autumn. Thus, the summer +DA is most effective in advecting sea ice out of the Arctic than the other seasons. The persistency of the +DA from winter, spring, to summer can be used to gauge the ice minimum occurrence under the present thinning ice conditions. 
2. The PIOMAS successfully captures almost all of the ice minima since 1995 , which compares very well to the satellite measurements. The key mechanisms were identified as DA-driven meridional wind anomaly that enhanced the advection of sea ice out of the PAR, and the enhanced thermodynamic melting via the positive ice/ocean albedo feedback process.

3. The + DA-derived wind anomaly not only drives away sea ice from the Pacific Arctic to the Atlantic Arctic, but also promotes the advection of more warm Bering water volume transport with anomalous heat transport, leading to ice minima in the PAR. In particular, the 2007 summer DA has the most parallel orientation to the TDS and Bering Strait than the summers of 2008, 2009, and 2010, thus leading to high volume and heat transports into the Chukchi Sea. The local N-S wind stress over the Bering Strait, which may not be associated with the DA pattern, is also important (Mizobata et al. 2010).

4. The Pacific Arctic atmosphere-ice-ocean interactions can be summarized by a feedback loop to explain the continuous ice decline and warmer water temperature in the Chukchi Sea in the last decade. The DA plays an important role as an external forcing to the ice-ocean system in the PAR. Once the +DA applies its forcing to the Pacific Arctic, a long-lasting impact on the sea ice reduction was observed. The key is the positive ice-ocean albedo feedback (Wang et al. 2005b; Shimada et al. 2006; Zhang et al. 2008a, b). Therefore, a series of +DA events (Wang et al. 2009a) should apply a series of pulses of positive ice-ocean albedo feedbacks into the PAR ice-ocean system. A possible reversal may be accomplished by -DA events. The ice-cloud feedback is another mechanism for continuous, further reduction of sea ice in the PAR.

5. The Bering shelf cold pool has significant impacts on ecosystems and fisheries distribution. The winter cold water is preserved in the middle shelf throughout the summer due to a stable, stratified temperature structure, and also due to the lack of effective horizontal heat transport and mixing from the deep basin and the inner shelf. Interannual variability of the cold pool extent/volume depends on winter meteorological and oceanic conditions, and winter ocean deep convection.

6. The key aspects of the major dynamic and thermodynamic processes of the landfast ice were captured by the CIOM. The major factors include the shallow, narrow shelf in contrast to the deep shelfbreak, and the deep basin (in terms of heat content), prevailing onshore wind forcing, and the warm ACC and the Slope Current. The largest variability occurs in spring and autumn, indicating that the melting and freezing seasons are the key periods. There are both strong interannual and significant decadal variability in landfast ice. The duration of landfast ice for the period of 1990-1997 was longer than that during 1998-2007. The landfast ice reduced significantly during spring of 2007, possibly due to the impacts of the persistent +DA anomaly from winter to summer of 2007 (Wang et al. 2009a). However, the anchoring process of the landfast ice by grounded pressure ridges is currently not included in the model and needs to be represented for a full evaluation of coastal ice dynamics. 
The Arctic Ocean and the PAR in particular have experienced rapid changes not only in sea ice and ocean, but also in ecosystems, in particular in the last decade. This study has discussed several important processes in the region. There is urgent need for a better understanding of these processes or hypotheses using combined long-term measurements and ice-ocean models. The following processes may be of interest:

1. There was a significant change in climate between the early 1990s and last decade. The +AO dominated in the early 1990s (cyclonic anomalous circulation), while the + DA prevailed in the last decade (meridional anomalous circulation), leading to significant ice reduction. These two leading climate modes should be the major forcing to other subsystems, such as sea ice, ocean, and ecosystem. Therefore, to adequately address the Arctic processes, the combined impact of these two modes is necessary.

2. The Bering Strait is a pathway of freshwater (volume transport) and heat to the Arctic Ocean and was more abnormal in the last decades. The connection between the Bering Strait and Fram Strait-Barents Sea opening, along with the Canadian Arctic Archipelagos (CAA) is not well known. A high-resolution coupled ice-ocean model that can resolve CAA is a high priority.

With diminishing summer ice in the Pacific Arctic, a northward migration of ecosystems is an urgent topic to be studied. The changes of food webs, lower trophic level ecosystems, and fisheries can have large impacts on the future planning and management of marine resources.

Acknowledgments We are grateful for supports from NOAA Arctic Program of the NOAA Climate Program Office to J.O. and J.W., NSF grants ARC-0611967, ARC0901987 and ARC0908769 to J.Z., NSF grant ARC-0714078 to Y.Y., H.E., and J.W., and the Ministry of Education, Science, Sports and Culture, Grant-in-Aid for Scientific Research from the Japan Society for the Promotion of Science to K.M. Thanks also go to Cathy Darnell of NOAA GLERL for editing this paper. We also sincerely thank Dr. Stephen Okkonen of UAF for his constructive comments on this paper. This is GLERL Contribution No. 1623, and PMEL Contribution No. 3837.

\section{References}

Blumberg A, Mellor G (1987) A description of 3-D coastal ocean circulation model. In: Heaps NS (ed) Coastal and estuarine sciences 4: 3-D coastal ocean models. American Geophysical Union, Washington, DC, pp 1-16

Clement Kinney J, Maslowski W, Okkonen S (2009) On the processes controlling shelf-basin exchange and outer shelf dynamics in the Bering Sea. Deep-Sea Res II 56:1351-1362. doi:10.1016/j.dsr2.2008.10.023

Clement Kinney J et al (2014) Chapter 7: On the flow through Bering Strait: a synthesis of model results and observations. In: Grebmeier JM, Maslowski W (eds) The Pacific Arctic region: ecosystem status and trends in a rapidly changing environment. Springer, Dordrecht, pp 167-198

Comiso J, Parkinson C, Gersten R, Stock L (2008) Accelerated decline in the Arctic sea ice cover. Geophys Res Lett 35:L01703. doi:10.1029/2007GL031972 
Deal C, Steiner N, Christian J, Clement Kinney J, Denman K, Elliott S, Gibson G, Jin M, Lavoie D, Lee S, Lee W, Maslowski W, Wang J, Watanabe E (2014) Chapter 12: Progress and challenges in biogeochemical modeling of the Pacific Arctic region. In: Grebmeier JM, Maslowski W (eds) The Pacific Arctic region: ecosystem status and trends in a rapidly changing environment. Springer, Dordrecht, pp 393-446

Eicken H, Shapiro L, Gaylord A, Mahoney A, Cotter P (2006) Mapping and characterization of recurring spring leads and landfast ice in the Beaufort and Chukchi seas. U.S. Department of Interior, Minerals Management Service (MMS), Alaska Outer Continental Shelf Region, Anchorage, $141 \mathrm{pp}$

Eicken H, Lovecraft AL, Druckenmiller ML (2009) Sea-ice system services: a framework to help identify and meet information needs relevant for Arctic observing networks. Arctic 62(2):119-136

Gascard J et al (2008) Exploring Arctic Transpolar Drift during drastic sea ice retreat. EOS 89(3):21-22

Grebmeier JM, Overland JE, Moore SE et al (2006) A major ecosystem shift in the northern Bering Sea. Science 311(5766):1461-1464. doi:10.1126/science.1121365

Grebmeier J, Moore S, Overland J, Frey K, Gradinger R (2010) Biological response to recent Pacific Arctic sea ice retreats. EOS 91(18):161-162

Haapala J, Meier H, Rinne J (2001) Numerical investigations of future ice conditions in the Baltic Sea. Ambio 30(4-5):237-244

Hibler W (1979) A dynamic and thermodynamic sea ice model. J Phys Oceanogr 9:15959-15969

Hibler W (1980) Modeling a variable thickness sea ice cover. Mon Weather Rev 108:1943-1973

$\mathrm{Hu} \mathrm{H}$, Wang J (2010) Modeling effects of tidal and wave mixing on circulation and thermohaline structures in the Bering Sea: process studies. J Geophys Res 115:C01006. doi:10.1029/200 $8 \mathrm{JC} 005175$

Hu H, Wang J, Wang D (2011) A model-data study of the 1999 St. Lawrence Island polynya in the Bering Sea. J Geophys Res 116:C12018. doi:10.1029/2011JC007309

Hufford G, Husby D (1972) Oceanographic survey of the Gulf of Anadyr August 1970, U.S. Coast Guard oceanography report CG-373-52. U.S. Coast Guard Oceanographic Unit, Washington, DC

Ikeda M (2012) Sea-ice cover anomalies in the Arctic Basin associated with the atmospheric variability from multi-decadal trend to intermittent quasi-biennial oscillations. Polar Res 31: 18690. http://dx.doi.org/10.3402/polar.v31i0.18690

Ikeda M, Wang J, Zhao JP (2001) Hypersensitive decadal oscillations in the Arctic/subarctic climate. Geophys Res Lett 28:1275-1278

Ikeda M, Wang J, Makshtas A (2003) Importance of clouds to the decaying trend and decadal variability in the Arctic ice cover. J Meteorol Soc 81:179-189

Jin M, Wang J, Mizobata K, Hu H, Shimada K (2008) Observations and modeling of the ice-ocean conditions in the coastal Chukchi and Beaufort Seas. Acta Oceanol Sin 27(3):79-87

Jin M, Deal C, Lee S, Elliott S, Hunke E, Maltrud M, Jeffery N (2011) Investigation of Arctic sea ice and ocean primary production for the period 1992 to 2007 using a 3-D global ice ecosystem model. Deep-Sea Res II 81-84:28-35. doi:10.1016/j.dsr2.2011.06.003

Kinder TH, Coachman LK (1978) The front overlaying the continental slope of the eastern Bering Sea. J Geophys Res 83:4551-4559

Kinder TH, Schumacher JD (1981) Circulation over the continental shelf of the southeastern Bering Sea. In: Hood DW, Calder JA (eds) The Eastern Bering Sea shelf: oceanography and resource, vol 1. Published by the Office of Marine Pollution Assessment, NOAA and BLM, Distributed by the University of Washington, Seattle, pp 53-76

König Beatty C, Holland DM (2010) Modeling landfast sea ice by adding tensile strength. J Phys Oceanogr 40(1):185-198

Kwok R (2008) Summer sea ice motion from the $18 \mathrm{GHz}$ channel of AMSR-E and the exchange of sea ice between the Pacific and Atlantic sectors. Geophys Res Lett 35:L03504. doi:10.1029/ 2007GL032692

Kwok R, Cunningham GF, Pang SS (2004) Fram Strait sea ice outflow. J Geophys Res 109:C01009. doi:10.1029/2003JC001785 
Lindsay RW, Zhang J, Schweiger AJ, Steele MA, Stern H (2009) Arctic sea ice retreat in 2007 follows thinning trend. J Clim 22:165-176. doi:10.1175/2008JCLI2521

Long Z, Perrie W, Tang CL, Dunlap E, Wang J (2012) Simulated interannual variations of freshwater content and sea surface height in the Beaufort Sea. J Clim 25:1079-1095. doi:10.1175/2 011JCI14121.1

Maeda T, Fujii T, Masuda K (1967) On the oceanographic condition and distribution of fish shoals in 1963 (in Japanese). Part 1. Studies on the trawl fishing grounds of the eastern Bering Sea. Bull Jap Soc Sci Fish 33(8):713-720

Mahoney A, Eicken H, Gaylord AG, Shapiro L (2007) Alaska landfast sea ice: links with bathymetry and atmospheric circulation. J Geophys Res 112:C02001. doi:10.1029/2006JC003559

Maslanik J, Drobot S, Fowler C, Emery W, Barry R (2007) On the Arctic climate paradox and the continuing role of atmospheric circulation in affecting sea ice conditions. Geophys Res Lett 34:L03711. doi:10.1029/2006GL028269

Maslanik J, Stroeve J, Fowler C, Emery W (2011) Distribution and trends in Arctic sea ice age through spring 2011. Geophys Res Lett 38:L13502. doi:10.1029/2011GL047735

Meier HEM (2002a) Regional ocean climate simulations with a 3D ice-ocean model for the Baltic Sea. Part 1: Model experiments and results for temperature and salinity. Clim Dyn 19:237-253

Meier HEM (2002b) Regional ocean climate simulations with a 3D ice-ocean model for the Baltic Sea. Part 2: Results for sea ice. Clim Dyn 19:255-266

Mizobata K, Saitoh S (2004) Variability of Bering Sea eddies and primary productivity along the shelf edge during 1998-2000 using satellite multi-sensor remote sensing. J Mar Syst 50:101-111

Mizobata K, Saitoh S, Shiomoto S, Miyamura T, Shiga N, Toratani M, Kajiwara Y, Sasaoka K (2002) Bering Sea cyclonic and anticyclonic eddies observed during summer 2000 and 2001. Prog Oceanogr 55:65-75

Mizobata K, Wang J, Saitoh S (2006) Eddy-induced cross-slope exchange maintaining summer high productivity of the Bering Sea shelf break. J Geophys Res 111:C10017. doi:10.1029/200 5JC003335

Mizobata K, Saitoh S, Wang J (2008) Interannual variability of summer biochemical enhancement in relation to the mesoscale eddy at the shelf break in the vicinity of the Pribilof Islands, Bering Sea. Deep Sea Res II 55:1717-1728. doi:10.1016/j.dsr2.2008.03.002

Mizobata K, Shimada K, Woodgate R, Saitoh S, Wang J (2010) Estimation of heat flux through the eastern Bering Strait. J Oceanogr 66(3):405-424. doi:10.1007/s10872-010-0035-7

Nghiem SV, Rigor IG, Perovich DK, Clemente-Colón P, Weatherly JW, Neumann G (2007) Rapid reduction of Arctic perennial sea ice. Geophys Res Lett 34:L19504. doi:10.1029/200 7GL031138

Niebauer HJ (1980) Sea ice and temperature variability in the eastern Bering Sea and relation to atmospheric fluctuations. J Geophys Res 85:7507-7515

Overland JE, Stabeno PJ (2004) Is the climate of the Bering Sea warming and affecting the ecosystems? EOS 85(33):309-316

Overland JE, Wang M, Salo S (2008) The recent Arctic warm period. Tellus A 60:589-597

Overland JE, Wang M, Wood KR, Percival DB, Bond NA (2012) Recent Bering Sea warm and cold events in a 95-year context. Deep-Sea Res II 65-70:6-13. doi:10.1016/j.dsr2.2012.02.013

Overland JE, Wang J, Pickart RS, Wang M (2014) Chapter 2: Recent large shifts in the meteorology of the Pacific Arctic region. In: Grebmeier J, Maslowski W (eds) The Pacific Arctic region: ecosystem status and trends in a rapidly changing environment. Springer, Dordrecht, pp 17-30

Pease CH, Salo SA, Overland JE (1983) Drag measurements for first-year sea ice over shallow sea. J Geophys Res 88(C5):2853-2862

Perovich DK, Richter-Menge JA, Jones KF, Light B (2008) Sunlight, water, and ice: extreme Arctic sea ice melt during the summer of 2007. Geophys Res Lett 35:L11501. doi:10.1029/20 08GL034007

Pickart RS (2004) Shelfbreak circulation in the Alaskan Beaufort Sea: mean structure and variability. J Geophys Res 109:C04024. doi:10.1029/2003JC001912 
PMEL (2000) FY 2000 operating plan. http://www.pmel.noaa.gov/home/accomp/opplan00.html

Proshutinsky AY, Johnson MA (1997) Two circulation regimes of the wind-driven Arctic Ocean. J Geophys Res 102(C6):12493-12514. doi:10.1029/97JC00738

Rigor IG, Wallace JM (2004) Variations in the age of Arctic sea-ice and summer sea-ice extent. Geophys Res Lett 31:L09401. doi:10.1029/2004GL019492

Serreze MC, Holland MM, Stroeve J (2007) Perspectives on the Arctic's shrinking sea ice cover. Science 315:1533. doi:10.1126/science. 1139426

Shimada K et al (2006) Pacific Ocean inflow: influence on catastrophic reduction of sea ice cover in the Arctic Ocean. Geophys Res Lett 33:L08605. doi:10.1029/2005GL025624

Springer AM, McRoy CP, Flint MV (1996) The Bering Sea Green Belt: shelf-edge processes and ecosystem productivity. Fish Oceanogr 35:205-223

Stabeno PJ, Reed RK (1994) Lagrangian measurements in the Kamchatka current and Oyashio. J Oceanogr 50:653-662

Stabeno PJ, Schumacher DJ, Ohtani K (1999) The physical oceanography of the Bering Sea. In: Loughlin TR, Ohtani K (eds) Dynamics Bering Sea. North Pacific Marine Science Organization (PICES), Published by University by Alaska Sea Grant, Fairbanks, Alaska, pp 1-28

Steele M, Morison J, Ermold W, Rigor I, Ortmeyer M, Shimada K (2004) Circulation of summer Pacific halocline water in the Arctic Ocean. J Geophys Res 109:C02027. doi:10.1029/200 3JC002009

Steele MW, Ermold W, Zhang J (2008) Arctic Ocean surface warming trends over the last 100 years. Geophys Res Lett 35:L0261

Takenouti Y, Ohtani KY (1974) Currents and water masses in the Bering Sea: a review of Japanese work. In: Hood DW, Kelley EJ (eds) Oceanography of the Bering Sea: with emphasis on renewable resources. Institute of Marine Science, University of Alaska, Fairbanks, pp 39-58

Wang J, Ikeda M (1997) Diagnosing ocean unstable baroclinic waves and meanders using quasigeostrophic equations and Q-vector method. J Phys Oceanogr 27:1157-1172

Wang J, Ikeda M (2000) Arctic oscillation and Arctic Sea-ice oscillation. Geophys Res Lett 27(9):1287-1290

Wang J, Ikeda M (2001) Arctic Sea-ice oscillation: regional and seasonal perspectives. Ann Glaciol 33:481-492

Wang J, van der Baaren A, Mysak LA (1995) A principal component analysis of gridded global sea-level pressure, surface air temperature and sea-ice concentration in the Arctic region, 19531993. C²GCR report No. 95-4, McGill University, Montreal, 22 pp + Figures + Fortran source programs. Available from jia.wang @ noaa.gov

Wang J, Liu Q, Jin M (2002) A user's guide for a Coupled Ice-Ocean Model (CIOM) in the PanArctic and North Atlantic Oceans. International Arctic Research Center-Frontier Research System for Global Change, Tech Res 02-01, $65 \mathrm{pp}$

Wang J, Kwok R, Saucier FJ, Hutchings J, Ikeda M, Hibler W III, Haapala J, Coon MD, Meier HEM, Eicken H, Tanaka N, Prentki R, Johnson W (2003) Working towards improved smallscale sea ice and ocean modeling in the Arctic seas. EOS 84(34):329-330

Wang J, Wu B, Tang C, Walsh JE, Ikeda M (2004) Seesaw Structure of subsurface temperature anomalies between the Barents Sea and the Labrador Sea. Geophys Res Lett 31:L19301. doi:10.1029/2004GL019981

Wang J, Liu Q, Jin M, Ikeda M, Saucier FJ (2005a) A coupled ice-ocean model in the pan-Arctic and the northern North Atlantic Ocean: simulation of seasonal cycles. J Oceanogr 61:213-233

Wang J, Ikeda M, Zhang S, Gerdes R (2005b) Linking the northern hemisphere sea ice reduction trend and the quasi-decadal Arctic Sea ice oscillation. Clim Dyn 24:115-130. doi:10.1007/ s00382-004-0454-5

Wang J, Mizobata K, Hu H, Jin M, Zhang S, Johnson W, Shimada K (2008) Modeling seasonal variations of ocean and sea ice circulation in the Beaufort and Chukchi seas: a model-data fusion study. Chin J Polar Sci 19(2):168-184

Wang J, Zhang J, Watanabe E, Mizobata K, Ikeda M, Walsh JE, Bai X, Wu B (2009a) Is the dipole anomaly a major driver to record lows in the Arctic sea ice extent? Geophys Res Lett 36:L05706. doi:10.1029/2008GL036706 
Wang J, Hu H, Mizobata K, Saitoh S (2009b) Seasonal variations of sea ice and ocean circulation in the Bering Sea: a model-data fusion study. J Geophys Res 114:C02011. doi:10.1029/200 8JC004727

Wang J, Mizobata K, Jin M, Hu H (2010) Sea Ice-Ocean-Oilspill Modeling System (SIOMS) for the nearshore Beaufort and Chukchi seas: parameterization and improvement (Phase II), Coastal Marine Institute report and OCS study MMS 2008-021. Coastal Marine Institute, Fairbanks, $88 \mathrm{pp}$

Wang M, Overland JE (2009) A sea ice free summer Arctic within 30 years? Geophys Res Lett 36:L07502. doi:10.1029/2009GL037820

Watanabe E, Wang J, Sumi T, Hasumi H (2006) Arctic Dipole and its contribution to sea ice exports in the last 20th century. Geophys Res Lett 33:L23703. doi:10.1029/2006GL028112

Woodgate RA, Aagaard K (2005) Revising the Bering Strait freshwater flux into the Arctic Ocean. Geophys Res Lett 32:L02602. doi:10.1029/2004GL021747

Woodgate RA, Weingartner TJ, Aagaard K (2005) A year in the physical oceanography of the Chukchi Sea: moored measurements from autumn 1990-1991. Deep Sea Res II 52:3116-3149

Woodgate RA, Weingartner T, Lindsay R (2010) The 2007 Bering Strait oceanic heat flux and anomalous Arctic sea-ice retreat. Geophys Res Lett 37:L01602. doi:10.1029/2009GL041621

Wu B, Wang J, Zhang R (2004) Effects of intraseasonal variations of the Arctic Oscillation on the Barents Sea. Polar Meteorol Glaciol 18:82-95

Wu B, Wang J, Walsh JE (2006) Dipole anomaly in the winter Arctic atmosphere and its association with Arctic sea ice motion. J Clim 19(2):210-225. doi:10.1175/JCLI3619.1

Wyllie-Echeverria T (1995) Seasonal sea ice, the cold pool and gadid distribution on the Bering Sea Shelf. PhD thesis, University of Alaska, Fairbanks, Alaska, 281 pp

Yao T, Tang CL, Peterson IK (2000) Modeling the seasonal variation of sea ice in the Labrador Sea with a coupled multi-category ice model and the Princeton Ocean Model. J Geophys Res 105:1153-1165

Zhang J, Lindsay RW, Steele M, Schweiger A (2008a) What drove the dramatic retreat of Arctic sea ice during summer 2007? Geophys Res Lett 35. doi:10.1029/2008GL03400

Zhang J, Steele M, Woodgate R (2008b) The role of Pacific water in the dramatic retreat of Arctic sea ice during summer 2007. Chin J Polar Sci 19(2):93-107

Zhang J, Woodgate R, Moritz R (2010) Sea ice response to atmospheric and oceanic forcing in the Bering Sea. J Phys Oceanogr 40:1729-1747. doi:10.1175/2010JPO4323.1 